\title{
chemosensors
}

ISSN 2227-9040

www.mdpi.com/journal/chemosensors

Article

\section{Synthesis and Properties of 2'-Deoxyuridine Analogues Bearing Various Azobenzene Derivatives at the C5 Position}

\author{
Shohei Mori ${ }^{1}$, Kunihiko Morihiro ${ }^{1,2, *}$, Yuuya Kasahara ${ }^{1,2}$, Shin-ichi Tsunoda ${ }^{2}$, and \\ Satoshi Obika ${ }^{1,2, *}$
}

1 Graduate School of Pharmaceutical Sciences, Osaka University, 1-6 Yamadaoka, Suita, Osaka 565-0871, Japan; E-Mails: mori-s@ phs.osaka-u.ac.jp (S.M.); y-kasahara@ nibio.go.jp (Y.K.)

2 National Institute of Biomedical Innovation (NIBIO), 7-6-8 Saito-Asagi, Osaka 567-0085, Japan;

E-Mail: tsunoda@nibio.go.jp

* Authors to whom correspondence should be addressed;

E-Mails: k-morihiro@nibio.go.jp (K.M.); obika@ phs.osaka-u.ac.jp (S.O.);

Tel.: +81-72-641-9882 (K.M.); +81-6-6879-8200 (S.O.);

Fax: +81-72-641-9884 (K.M.); +81-6-6879-8204 (S.O.).

Academic Editor: Patrick Hrdlicka

Received: 4 September 2014 / Accepted: 9 March 2015 / Published: 27 March 2015

\begin{abstract}
Nucleic acids that change their properties upon photo-irradiation could be powerful materials for molecular sensing with high spatiotemporal resolution. Recently, we reported a photo-isomeric nucleoside bearing azobenzene at the $\mathrm{C} 5$ position of 2'-deoxyuridine $\left(\mathbf{d} \mathbf{U}^{\mathbf{A z}}\right)$, whose hybridization ability could be reversibly controlled by the appropriate wavelength of light. In this paper, we synthesized and evaluated $\mathbf{d} \mathbf{U}^{\mathbf{A z}}$ analogues that have various para-substitutions on the azobenzene moiety. Spectroscopic measurements and HPLC analyses revealed that the para-substitutions of the azobenzene moiety strongly affect the photo-isomerization ability and thermal stability of the cis-form. The results suggest that proper substitution of the azobenzene moiety can improve the properties of $\mathbf{d} \mathbf{U}^{\mathbf{A z}}$ as a light-responsive nucleic acid probe.
\end{abstract}

Keywords: azobenzene; nucleoside; nucleic acid probe; oligonucleotide; photochromism 


\section{Introduction}

Much attention has been focused on chemically modified nucleic acids that can alter their properties by some external stimuli [1-3]. Photo-responsive nucleic acids have been realized by regulation of hydrogen bonding [4] and stacking effects [5] between nucleobases. Light is considered to be a promising external stimulus due to the possibility of accurately controlling the location, dosage, and time of the irradiation. Various photochromic derivatives have been attached to nucleic acids to photo-control their properties [6]. For example, diarylethene-modified oligonucleotides (ONs) showed changes in their optical properties [7,8] and hybridization abilities [8] by photo-isomerization. However, the changes in hybridization abilities were moderate and the diarylethene modification itself destabilized the DNA duplex in both forms. To obtain a significant melting temperature difference $\left(\Delta T_{\mathrm{m}}\right)$ upon photo-isomerization, ONs containing cis-trans type photochromic derivatives have been reported. Owing to their dynamic structural changes upon photo-irradiation, cis-trans type photochromic derivatives could greatly influenced the stability of nucleic acid duplexes. Although stilbene-type derivative-modified ONs have been utilized for photo-control of duplex formation, G-quadruplex formation, and gene expression, they require short wavelength photo-irradiation for cis to trans isomerization [9-11]. This would be disadvantageous for biomolecules due to photo-damaging reactions including the formation of pyrimidine dimers [12]. Azobenzene derivative-modified ONs are quite promising photochromic ONs because they can rapidly photo-isomerize by longer wavelengths of light $[13,14]$. Asanuma et al. have demonstrated that ONs modified with azobenzene moieties could be utilized as photo-responsive tweezers, RNA scission, and engines [15]. Recently, we reported that the ON containing C5-azobenzene-substituted 2'-deoxyuridine $\left(\mathbf{d U}^{\mathbf{A z}}\right)$ could be photo-isomerized from trans to cis with an efficiency of $60 \%$ by UV light $(365 \mathrm{~nm})$ and from cis to trans with an efficiency of $80 \%$ by visible light $(450 \mathrm{~nm})$ [16]. The $\mathrm{ON}$ containing $\mathbf{d} \mathbf{U}^{\mathbf{A z}}$ showed interesting hybridization properties, namely, the $T_{\mathrm{m}}$ values of the duplexes formed between $\mathbf{d U}^{\mathbf{A z}}$-modified ON and complementary DNA or RNA were higher after UV irradiation than before irradiation. This may be because the hydrophobic azobenzene in the trans form extends to the outside of the groove and interferes with hydration and the formation of interstrand cation bridges to stabilize the duplexes. Meanwhile, cis-d $\mathbf{d} \mathbf{U}^{\mathbf{A z}}$ did not affect the duplex stability due to the compact conformation of the azobenzene moiety. These results indicated that $\mathbf{d} \mathbf{U}^{\mathbf{A z}}$ could be a potential building block to control nucleic acid hybridization with high spatiotemporal resolution.

In this study, we describe the synthesis and properties of $\mathbf{d U}^{\mathbf{A z}}$ analogues bearing various para-substituted azobenzene derivatives (Figure 1). The isomerization properties of photochromic compounds have been proposed to be strongly influenced by substituents [17]. Thus, the introduction of electron-donating or -withdrawing substituents into the azobenzene moiety could improve the properties of $\mathbf{d} \mathbf{U}^{\mathbf{A z}}$ and create unique photo-sensors for various biomolecules. 


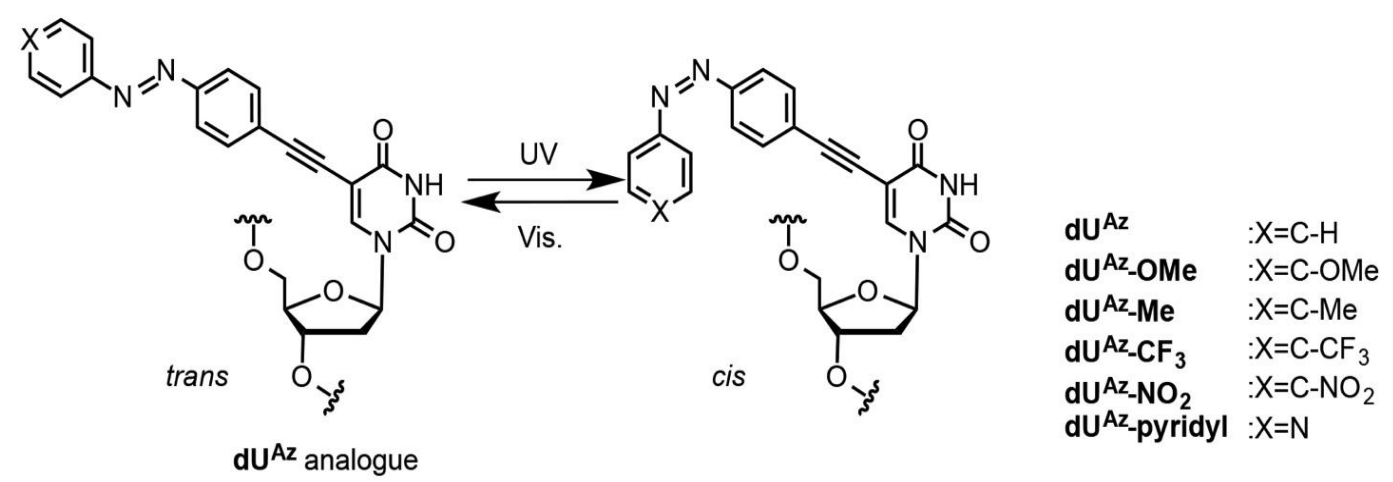

Figure 1. Para-substituted $\mathbf{d} \mathbf{U}^{\mathbf{A z}}$ analogues used in this study.

\section{Experimental Section}

\subsection{General}

Reagents and solvents were purchased from commercial suppliers and were used without purification unless otherwise specified. All experiments involving air- and/or moisture-sensitive compounds were carried out under $\mathrm{N}_{2}$ or Ar atmosphere. All reactions were monitored with analytical TLC (Merck Kieselgel 60 F254; Merck, Darmstadt, Germany). Column chromatography was carried out using FL-100D silica gel (Fuji Silysia, Aichi, Japan). Physical data were measured as follows. NMR spectra were recorded on JNM-ECS-300, JNM-ECS-400, and JNM-ECS-500 spectrometers (JEOL, Tokyo, Japan) using $\mathrm{CDCl}_{3}$ or DMSO- $d_{6}$ as solvents with tetramethylsilane as an internal standard. IR spectra were recorded on a FT/IR-4200 spectrophotometer (JASCO, Tokyo, Japan). Optical rotations were recorded on a JASCO P-2200 instrument. FAB mass spectra were measured on a JEOL JMS-700 mass spectrometer. Solid-phase ON synthesis was performed on an nS-8 Oligonucleotide Synthesizer (GeneDesign, Osaka, Japan). MALDI-TOF mass spectra were recorded on an ultrafleXtreme mass spectrometer (Bruker Daltonics, Billerica, MA, USA) for oligonucleotides and on a JMS-S3000 (JEOL, Tokyo, Japan) for small molecules. Photo-irradiation experiments were conducted with a Xenon lamp (MAX-303; Asahi Spectra, Tokyo, Japan) using HQBP 450-VIS $\varnothing 25$ and 365-VIS $\varnothing 25$ as the optical filters. UV/Vis absorption measurements and UV melting experiments were performed using a UV-1650PC UV-Vis spectrophotometer equipped with a TMSPC-8 $T_{\mathrm{m}}$ analysis accessory (Shimadzu, Kyoto, Japan). ITC experiments were performed using a Microcal iTC 200 (Malvern Instruments, Worcestershire, UK).

\subsection{Preparation of 4-[4-(trimethylsilyl)ethynylphenylazo]pyridine (2)}

Under an argon atmosphere, 4-(4-iodophenylazo)pyridine 1 [18] (950 mg, $3.07 \mathrm{mmol}$ ) was dissolved in dry THF (30 mL). Pd(PPh $)_{4}(358 \mathrm{mg}, 0.310 \mathrm{mmol}), \mathrm{CuI}(59.0 \mathrm{mg}, 0.310 \mathrm{mmol}), \mathrm{Et}_{3} \mathrm{~N}$ $(2.1 \mathrm{~mL}, 15.4 \mathrm{mmol})$, and trimethylsilylacetylene $(1.1 \mathrm{~mL}, 7.68 \mathrm{mmol})$ were then added. The reaction mixture was stirred at $60{ }^{\circ} \mathrm{C}$ for $6 \mathrm{~h}$. The resultant mixture was filtered over Celite. The filtrate was concentrated in vacuo. The residue was purified by silica gel column chromatography and eluted with hexane/AcOEt (8:1) to give compound 2 (485 mg, 57\%) as a red oil. IR (KBr): v $2156(\mathrm{C} \equiv \mathrm{C})$, $1250(\mathrm{~N}=\mathrm{N}) \mathrm{cm}^{-1} ;{ }^{1} \mathrm{H}-\mathrm{NMR}\left(400 \mathrm{MHz}, \mathrm{CDCl}_{3}\right): \delta 8.81(2 \mathrm{H}, \mathrm{dd}, J=2.0,4.5 \mathrm{~Hz}), 7.91(2 \mathrm{H}, \mathrm{dd}, J=1.5$, $6.5 \mathrm{~Hz}), 7.70(2 \mathrm{H}, \mathrm{dd}, J=1.5,4.5 \mathrm{~Hz}), 7.63(2 \mathrm{H}, \mathrm{dd}, J=2.0,6.5 \mathrm{~Hz}), 0.28(9 \mathrm{H}, \mathrm{s}) ;{ }^{13} \mathrm{C}-\mathrm{NMR}$ 
(100 MHz, $\left.\mathrm{CDCl}_{3}\right): \delta 151.5,151.4,133.0,132.5,130.4,129.3,123.5,123.4,116.33,116.31$; FAB-HRMS $\mathrm{m} / z\left(\mathrm{MH}^{+}\right)$calcd for $\mathrm{C}_{16} \mathrm{H}_{18} \mathrm{~N}_{3} \mathrm{Si}$ : 280.1265; found 280.1272 .

\subsection{Preparation of 4-(4-ethynylphenylazo)pyridine (5)}

Under an argon atmosphere, to a solution of compound 2 [19] (319 mg, $1.14 \mathrm{mmol}$ ) in dry THF $(5 \mathrm{~mL})$ were added $\mathrm{K}_{2} \mathrm{CO}_{3}(79 \mathrm{mg}, 0.57 \mathrm{mmol})$ and $\mathrm{MeOH}(5 \mathrm{~mL})$ and the reaction mixture was stirred for $2 \mathrm{~h}$ at room temperature. The resultant mixture was diluted with AcOEt $(30 \mathrm{~mL})$ and washed with $\mathrm{H}_{2} \mathrm{O}$, followed by brine. The organic layer was dried $\left(\mathrm{Na}_{2} \mathrm{SO}_{4}\right)$ and concentrated in vacuo. The residue was purified by silica gel column chromatography and eluted with hexane/AcOEt (3:1) to give compound 5 (205 mg, 86\%) as a red powder. M.p. $160{ }^{\circ} \mathrm{C}$ (decomposed); IR (KBr): $v 2092(\mathrm{C} \equiv \mathrm{C})$, $1263(\mathrm{~N}=\mathrm{N}) \mathrm{cm}^{-1} ;{ }^{1} \mathrm{H}-\mathrm{NMR}\left(400 \mathrm{MHz}, \mathrm{CDCl}_{3}\right): \delta 8.82(2 \mathrm{H}, \mathrm{dd}, J=1.5,4.5 \mathrm{~Hz}), 7.92(2 \mathrm{H}, \mathrm{d}$, $J=8.0 \mathrm{~Hz}), 7.71(2 \mathrm{H}, \mathrm{dd}, J=1.5,4.5 \mathrm{~Hz}), 7.66(2 \mathrm{H}, \mathrm{d}, J=9.0 \mathrm{~Hz}), 3.28(1 \mathrm{H}, \mathrm{s}) ;{ }^{13} \mathrm{C}-\mathrm{NMR}(100 \mathrm{MHz}$, $\left.\mathrm{CDCl}_{3}\right): \delta 157.0,151.8,151.4,133.1,126.2,123.3,116.2,83.0,80.3$; FAB-HRMS $m / z\left(\mathrm{MH}^{+}\right)$calcd for $\mathrm{C}_{13} \mathrm{H}_{10} \mathrm{~N}_{3}$ : 208.0869; found 208.0855.

\subsection{Preparation of 4-ethynyl-4'-methoxyazobenzene (6)}

Under an argon atmosphere, to a solution of compound 3 [19] (750 mg, $2.44 \mathrm{mmol}$ ) in dry THF (10 mL) were added $\mathrm{K}_{2} \mathrm{CO}_{3}(169 \mathrm{mg}, 1.22 \mathrm{mmol})$ and $\mathrm{MeOH}(10 \mathrm{~mL})$ and the reaction mixture was stirred for $2 \mathrm{~h}$ at room temperature. The resultant mixture was diluted with AcOEt ( $40 \mathrm{~mL}$ ) and washed with $\mathrm{H}_{2} \mathrm{O}$, followed by brine. The organic layer was dried $\left(\mathrm{Na}_{2} \mathrm{SO}_{4}\right)$ and concentrated in vacuo. The residue was purified by silica gel column chromatography and eluted with hexane/ $\mathrm{CH}_{2} \mathrm{Cl}_{2}$ (4:1) to give compound 6 (576 mg, 99\%) as an orange powder. M.p. 76-78 ${ }^{\circ} \mathrm{C}$; IR $(\mathrm{KBr}): v 2102(\mathrm{C} \equiv \mathrm{C}), 1252(\mathrm{~N}=\mathrm{N}) \mathrm{cm}^{-1}$; ${ }^{1} \mathrm{H}-\mathrm{NMR}\left(400 \mathrm{MHz}, \mathrm{CDCl}_{3}\right): \delta 7.81(2 \mathrm{H}, \mathrm{d}, J=8.5 \mathrm{~Hz}), 7.73(2 \mathrm{H}, \mathrm{d}, J=8.0 \mathrm{~Hz}), 7.51(2 \mathrm{H}, \mathrm{d}, J=8.0 \mathrm{~Hz})$, $6.89(2 \mathrm{H}, \mathrm{d}, J=9.0 \mathrm{~Hz}), 3.76(3 \mathrm{H}, \mathrm{s}), 3.11(1 \mathrm{H}, \mathrm{s}) ;{ }^{13} \mathrm{C}-\mathrm{NMR}\left(100 \mathrm{MHz}, \mathrm{CDCl}_{3}\right): \delta 162.3,152.3$, 146.9, 132.9, 124.9, 123.9, 122.4, 114.2, 83.4, 79.1, 55.5; FAB-HRMS $m / z\left(\mathrm{MH}^{+}\right)$calcd for $\mathrm{C}_{15} \mathrm{H}_{13} \mathrm{~N}_{2} \mathrm{O}: 237.1022$; found 237.1021.

\subsection{Preparation of 4-ethynyl-4'-methylazobenzene (7)}

Under an argon atmosphere, to a solution of compound 4 [19] (403 $\mathrm{mg}, 1.38 \mathrm{mmol}$ ) in dry THF $(6 \mathrm{~mL})$ were added $\mathrm{K}_{2} \mathrm{CO}_{3}(95 \mathrm{mg}, 0.69 \mathrm{mmol})$ and $\mathrm{MeOH}(6 \mathrm{~mL})$ and the reaction mixture was stirred for $2 \mathrm{~h}$ at room temperature. The resultant mixture was diluted with AcOEt $(20 \mathrm{~mL})$ and washed with $\mathrm{H}_{2} \mathrm{O}$, followed by brine. The organic layer was dried $\left(\mathrm{Na}_{2} \mathrm{SO}_{4}\right)$ and concentrated in vacuo. The residue was purified by silica gel column chromatography and eluted with hexane to give compound 7 (203 mg, 92\%) as an orange powder. M.p. $138-140{ }^{\circ} \mathrm{C}$; IR (KBr): v $2156(\mathrm{C} \equiv \mathrm{C})$, $1250(\mathrm{~N}=\mathrm{N}) \mathrm{cm}^{-1} ;{ }^{1} \mathrm{H}-\mathrm{NMR}\left(300 \mathrm{MHz}, \mathrm{CDCl}_{3}\right): \delta 7.87-781(4 \mathrm{H}, \mathrm{m}), 7.61(2 \mathrm{H}, \mathrm{d}, J=8.5 \mathrm{~Hz}), 7.30$ $(2 \mathrm{H}, \mathrm{d}, J=8.5 \mathrm{~Hz}), 3.21(1 \mathrm{H}, \mathrm{s}), 2.42(3 \mathrm{H}, \mathrm{s}) ;{ }^{13} \mathrm{C}-\mathrm{NMR}\left(125 \mathrm{MHz}, \mathrm{CDCl}_{3}\right): \delta 152.2,150.7,142.0$, 132.9, 129.8, 124.3, 123.0, 122.7, 83.3, 79.3, 21.5; MALDI-TOF-HRMS $\mathrm{m} / z\left(\mathrm{MH}^{+}\right)$calcd for $\mathrm{C}_{15} \mathrm{H}_{13} \mathrm{~N}_{2}: 221.1073$; found 221.1075. 


\subsection{Preparation of 5-[4-(4-pyridyl)diazenylphenyl]ethynyl-2'-deoxyuridine (11)}

Under an argon atmosphere, compound 5 (281 mg, $1.35 \mathrm{mmol})$ was dissolved in dry DMF (15 mL). $\mathrm{Pd}\left(\mathrm{PPh}_{3}\right)_{4}(156 \mathrm{mg}, 0.135 \mathrm{mmol}), \mathrm{CuI}(26 \mathrm{mg}, 0.135 \mathrm{mmol}), \mathrm{Et} 3 \mathrm{~N}(940 \mu \mathrm{L})$, and 2'-deoxy-5-iodouridine 10 (466 mg, $1.35 \mathrm{mmol}$ ) were then added. The reaction mixture was stirred at $60{ }^{\circ} \mathrm{C}$ for $12 \mathrm{~h}$. The resultant mixture was filtered over Celite. The filtrate was concentrated in vacuo. The residue was purified by silica gel column chromatography and eluted with DMF to give compound 11 (295 mg, $50 \%)$ as a red powder. M.p. $235{ }^{\circ} \mathrm{C}$ (decomposed); IR $(\mathrm{KBr}): v 3250(\mathrm{NH}, \mathrm{OH}), 1636(\mathrm{C}=\mathrm{O}) ;[\alpha]_{\mathrm{D}}{ }^{24}$ -19.6 (c 1.00, DMSO); ${ }^{1} \mathrm{H}-\mathrm{NMR}$ (500 MHz, DMSO- $\left.d 6\right): \delta 11.7(1 \mathrm{H}$, br s, NH), $8.82(2 \mathrm{H}, \mathrm{d}, J=4.5 \mathrm{~Hz})$, $8.48(1 \mathrm{H}, \mathrm{s}, \mathrm{H}-6), 7.96(2 \mathrm{H}, \mathrm{d}, J=8.0 \mathrm{~Hz}), 7.75-7.68(4 \mathrm{H}, \mathrm{m}), 6.13\left(1 \mathrm{H}, \mathrm{t}, J=6.0 \mathrm{~Hz}, \mathrm{H}-1^{\prime}\right), 5.27(1 \mathrm{H}$, $\mathrm{d}, J=4.0 \mathrm{~Hz}, \mathrm{OH}), 5.21(1 \mathrm{H}, \mathrm{t}, J=4.5 \mathrm{~Hz}, \mathrm{OH}), 4.29-4.25\left(1 \mathrm{H}, \mathrm{m}, \mathrm{H}-3^{\prime}\right), 3.84-3.82\left(1 \mathrm{H}, \mathrm{m} . \mathrm{H}-4^{\prime}\right)$, 3.67-3.58 (2H, m, H-5'), 2.21-2.17 (2H, m, H-2'); ${ }^{13} \mathrm{C}-\mathrm{NMR}$ (125 MHz, DMSO-d6): $\delta$ 161.3, 156.5, 151.5, 150.8, 149.4, 144.68, 132.3, 126.8, 123.5, 115.9, 97.7, 91.4, 87.6, 85.4, 85.0, 69.8, 60.8, 40.3; MALDI-TOF-HRMS $m / z\left(\mathrm{MH}^{+}\right)$calcd for $\mathrm{C}_{22} \mathrm{H}_{20} \mathrm{~N}_{5} \mathrm{O}_{5}$ : 434.1459; found 434.1451.

\subsection{Preparation of 5-[4-(4-methoxyphenyl)diazenylphenyl]ethynyl-2'-deoxyuridine (12)}

Under an argon atmosphere, compound 6 (303 $\mathrm{mg}, 1.28 \mathrm{mmol})$ was dissolved in dry DMF (15 mL). $\mathrm{Pd}\left(\mathrm{PPh}_{3}\right)_{4}$ (148 mg, $\left.0.128 \mathrm{mmol}\right), \mathrm{CuI}(24 \mathrm{mg}, 0.128 \mathrm{mmol}), \mathrm{Et}_{3} \mathrm{~N}(1 \mathrm{~mL})$, and 2'-deoxy-5-iodouridine 10 (441 mg, $1.28 \mathrm{mmol}$ ) were then added. The reaction mixture was stirred at $60{ }^{\circ} \mathrm{C}$ for $12 \mathrm{~h}$. The resultant mixture was filtered over Celite. The filtrate was concentrated in vacuo. The residue was purified by silica gel column chromatography and eluted with $\mathrm{CHCl}_{3} / \mathrm{MeOH}(10: 1)$ to give compound 12 (360 mg, 61\%) as a light-orange powder. M.p. $253{ }^{\circ} \mathrm{C}$ (decomposed); IR (KBr): $v 3345(\mathrm{NH}, \mathrm{OH})$, $2102(\mathrm{C} \equiv \mathrm{C}), 1638(\mathrm{C}=\mathrm{O}) \mathrm{cm}^{-1} ;[\alpha]_{\mathrm{D}}{ }^{24}-21.6$ (c 1.00, DMSO); ${ }^{1} \mathrm{H}-\mathrm{NMR}$ (500 MHz, DMSO- $\left.d_{6}\right): \delta 11.7$ $(1 \mathrm{H}$, br s, NH), 8.47-8.44 (1H, m, H-6), 7.90-7.85 (4H, m), $7.64(2 \mathrm{H}, \mathrm{d}, J=6.0 \mathrm{~Hz}), 7.13(2 \mathrm{H}, \mathrm{d}$, $J=5.0 \mathrm{~Hz}), 6.18-6.11(1 \mathrm{H}, \mathrm{m}, \mathrm{H}-1 '), 5.31-5.25(1 \mathrm{H}, \mathrm{m}, \mathrm{OH}), 5.24-5.18(1 \mathrm{H}, \mathrm{m}, \mathrm{OH}), 4.32-4.24(1 \mathrm{H}, \mathrm{m}$, H-3'), 3.89-3.81 (4H, m, H-4', Ph-OMe), 3.70-3.59 (2H, m, H-5'), 2.23-2.14 (2H, m, H-2'); ${ }^{13} \mathrm{C}-\mathrm{NMR}$ (125 MHz, DMSO- $\left.d_{6}\right): \delta 162.3,161.3,151.2,149.4,146.2,144.3,132.2,124.8,122.6,114.7$, 97.9, 91.6, 87.6, 85.1, 84.9, 69.9, 60.8, 55.6, 40.3; FAB-HRMS $m / z\left(\mathrm{MH}^{+}\right)$calcd for $\mathrm{C}_{24} \mathrm{H}_{23} \mathrm{~N}_{4} \mathrm{O}_{6}$ : 463.1612; found 463.1613 .

\subsection{Preparation of 5-[4-(4-methylphenyl)diazenylphenyl]ethynyl-2'-deoxyuridine (13)}

Under an argon atmosphere, compound $7(280 \mathrm{mg}, 1.27 \mathrm{mmol})$ was dissolved in dry DMF (13 mL). $\mathrm{Pd}\left(\mathrm{PPh}_{3}\right)_{4}$ (173 mg, $\left.0.127 \mathrm{mmol}\right), \mathrm{CuI}$ (29 mg, $\left.0.127 \mathrm{mmol}\right), \mathrm{Et}_{3} \mathrm{~N}$ (1.33 mL), and 2'-deoxy-5-iodouridine $10(292 \mathrm{mg}, 0.846 \mathrm{mmol})$ were then added. The reaction mixture was stirred at $60{ }^{\circ} \mathrm{C}$ for $12 \mathrm{~h}$. The resultant mixture was filtered over Celite. The filtrate was concentrated in vacuo. The residue was purified by silica gel column chromatography and eluted with $\mathrm{CHCl}_{3} / \mathrm{MeOH}(10: 1)$ to give compound 13 (284 mg, 75\%) as a light-orange powder. M.p. $255^{\circ} \mathrm{C}$ (decomposed); IR (KBr): $v 3345(\mathrm{NH}, \mathrm{OH})$, $2091(\mathrm{C} \equiv \mathrm{C}), 1641(\mathrm{C}=\mathrm{O}) \mathrm{cm}^{-1}$; $[\alpha]_{\mathrm{D}}{ }^{24}-20.6$ (c 1.00, DMSO); ${ }^{1} \mathrm{H}-\mathrm{NMR}$ (500 MHz, DMSO- $\left.d_{6}\right): \delta 11.7$ $(1 \mathrm{H}$, br s, NH), 8.47-8.44 (1H, m, H-6), 7.92-7.79 (4H, m), 7.69-7.63 (2H, m), 7.43-7.38 (2H, m), 6.17-6.11 (1H, m, H-1'), 5.30-5.24 (1H, m, OH), 5.22-5.16 (1H, m, OH), 4.30-4.23 (1H, m, H-3'), 3.85-3.79 (1H, m, H-4'), 3.71-3.57 (2H, m, H-5'), 2.40 (3H, s), 2.22-2.13 (2H, m, H-2'); ${ }^{13} \mathrm{C}-\mathrm{NMR}$ 
(125 MHz, DMSO-d6): $\delta 161.3,151.1,150.1,149.4,144.4,142.2,132.2,130.0,125.1,122.8,97.7$, 91.4, 87.6, 85.4, 85.0, 69.8, 60.8, 40.3, 21.1; MALDI-TOF-HRMS $m / z\left(\mathrm{MH}^{+}\right)$calcd for $\mathrm{C}_{24} \mathrm{H}_{23} \mathrm{~N}_{4} \mathrm{O}_{5}$ : 447.1663; found 447.1663.

\subsection{Preparation of 5-[4-(4-trifluoromethylphenyl)diazenylphenyl]ethynyl-2'-deoxyuridine (14)}

Under an argon atmosphere, compound 8 [20] (369 mg, $1.35 \mathrm{mmol})$ was dissolved in dry DMF (15 mL). $\mathrm{Pd}\left(\mathrm{PPh}_{3}\right)_{4}$ (156 mg, $\left.0.135 \mathrm{mmol}\right), \mathrm{CuI}(26 \mathrm{mg}, 0.135 \mathrm{mmol}), \mathrm{Et}_{3} \mathrm{~N}(1 \mathrm{~mL})$, and 2'-deoxy-5-iodouridine 10 (465 mg, $1.35 \mathrm{mmol}$ ) were then added. The reaction mixture was stirred at $60{ }^{\circ} \mathrm{C}$ for $12 \mathrm{~h}$. The resultant mixture was filtered over Celite. The filtrate was concentrated in vacuo. The residue was purified by silica gel column chromatography and eluted with $\mathrm{CHCl}_{3} / \mathrm{MeOH}(10: 1)$ to give compound 14 (415 mg, $62 \%$ ) as a light-orange powder. M.p. $255^{\circ} \mathrm{C}$ (decomposed); $\mathrm{IR}(\mathrm{KBr}): v 3365(\mathrm{NH}, \mathrm{OH}), 1659(\mathrm{C}=\mathrm{O}) \mathrm{cm}^{-1}$; $[\alpha]_{\mathrm{D}}{ }^{24}-16.7$ (c 1.00, DMSO); ${ }^{1} \mathrm{H}-\mathrm{NMR}\left(500 \mathrm{MHz}, \mathrm{DMSO}-d_{6}\right): \delta 11.8(1 \mathrm{H}, \mathrm{br} \mathrm{s}, \mathrm{NH}), 8.50(1 \mathrm{H}, \mathrm{s}$, $\mathrm{H}-6), 8.08(2 \mathrm{H}, \mathrm{d}, J=8.0 \mathrm{~Hz}), 7.99(4 \mathrm{H}, \mathrm{d}, J=8.5 \mathrm{~Hz}), 7.71(2 \mathrm{H}, \mathrm{d}, J=8.0 \mathrm{~Hz}), 6.15(1 \mathrm{H}, \mathrm{t}$, $\left.J=6.5 \mathrm{~Hz}, \mathrm{H}-1^{\prime}\right), 5.29(1 \mathrm{H}, \mathrm{d}, J=3.5 \mathrm{~Hz}, \mathrm{OH}), 5.24-5.21(1 \mathrm{H}, \mathrm{m}, \mathrm{OH}), 4.29(1 \mathrm{H}, \mathrm{s}, \mathrm{H}-3$ '), $3.84(1 \mathrm{H}, \mathrm{d}$, $\left.J=3.5 \mathrm{~Hz}, \mathrm{H}-4^{\prime}\right), 3.71-3.61$ (2H, m, H-5'), 2.22-2.18 (2H, m, H-2'); ${ }^{13} \mathrm{C}-\mathrm{NMR}$ (125 MHz, DMSO- $\left.d_{6}\right)$ : $\delta 161.3,154.0,150.8,149.4,144.6,132.3,130.9,126.8,126.3,123.4,123.2$, 97.7, 91.4, 87.6, 86.2, 85.0, 79.2, 69.8, 60.8, 40.3; MALDI-TOF-HRMS $m / z\left(\mathrm{MNa}^{+}\right)$calcd for $\mathrm{C}_{24} \mathrm{H}_{19} \mathrm{~N}_{4} \mathrm{O}_{5} \mathrm{~F}_{3} \mathrm{Na}$ : 523.1200; found 523.1200 .

\subsection{Preparation of 5-[4-(4-nitrophenyl)diazenylphenyl]ethynyl-2'-deoxyuridine (15)}

Under an argon atmosphere, compound 9 [21] (302 mg, $1.20 \mathrm{mmol})$ was dissolved in dry DMF (15 mL). $\mathrm{Pd}\left(\mathrm{PPh}_{3}\right)_{4}(139 \mathrm{mg}, 0.120 \mathrm{mmol}), \mathrm{CuI}(23 \mathrm{mg}, 0.120 \mathrm{mmol}), \mathrm{Et} 3 \mathrm{~N}(1 \mathrm{~mL})$, and 2'-deoxy-5-iodouridine 10 (414 mg, $1.20 \mathrm{mmol}$ ) were then added. The reaction mixture was stirred at $60{ }^{\circ} \mathrm{C}$ for $12 \mathrm{~h}$. The resultant mixture was filtered over Celite. The filtrate was concentrated in vacuo. The residue was purified by silica gel column chromatography and eluted with $\mathrm{CHCl}_{3} / \mathrm{MeOH}(5: 1)$ to give compound 15 (545 mg, 95\%) as a red powder. M.p. $270{ }^{\circ} \mathrm{C}$ (decomposed); IR (KBr): v $3403(\mathrm{NH}, \mathrm{OH}), 1631(\mathrm{C}=\mathrm{O}) \mathrm{cm}^{-1}$; $[\alpha]_{\mathrm{D}}{ }^{24}-22.5$ (c 1.00, DMSO); ${ }^{1} \mathrm{H}-\mathrm{NMR}\left(500 \mathrm{MHz}, \mathrm{DMSO}-d_{6}\right): \delta 11.8(1 \mathrm{H}, \mathrm{br}, \mathrm{NH}), 8.50-8.44(3 \mathrm{H}$, m), 8.10-8.08 (2H, m), 8.02-7.97 (2H, m), 7.74-7.68 (2H, m), 6.17-6.11 (1H, m, H-1'), 5.30-5.28 (1H, m, OH), $5.22(1 \mathrm{H}, \mathrm{d}, J=4.5 \mathrm{~Hz}, \mathrm{OH}), 4.28$ (1H, m, H-3'), 3.84 (1H, m, H-4'), 3.68-3.62 (2H, m, H-5'), 2.22-2.18 (2H, m, H-2'); ${ }^{13} \mathrm{C}-\mathrm{NMR}$ (125 MHz, DMSO-d6): $\delta 161.3,155.0,150.9,149.4,148.6,144.7$, 132.3, 126.7, 125.1, 123.6, 123.5, 97.7, 91.5, 87.6, 86.5, 85.0, 69.8, 60.8, 40.3; MALDI-TOF-HRMS $\mathrm{m} / z\left(\mathrm{MNa}^{+}\right)$calcd for $\mathrm{C}_{23} \mathrm{H}_{19} \mathrm{~N}_{5} \mathrm{O}_{7} \mathrm{Na}: 500.1177$; found 500.1169 .

\subsection{Preparation of 5'-O-(4,4'-dimethoxytrityl)-5-[4-(4-pyridyl)diazenylphenyl]ethynyl-2'-deoxyuridine (16)}

To a solution of compound $11(147 \mathrm{mg}, 0.339 \mathrm{mmol})$ in dry pyridine $(4 \mathrm{~mL})$ was added $\mathrm{DMTrCl}$ (138 $\mathrm{mg}, 0.406 \mathrm{mmol}$ ) at room temperature, and the reaction mixture was stirred for $16 \mathrm{~h}$. The reaction was quenched by the addition of $\mathrm{MeOH}$ with $10 \mathrm{~min}$ stirring. The solvent was removed in vасиo, and the residue was partitioned between $\mathrm{CHCl}_{3}$ and $\mathrm{H}_{2} \mathrm{O}$. The separated organic layer was washed with $\mathrm{H}_{2} \mathrm{O}$, followed by brine. The organic layer was dried $\left(\mathrm{Na}_{2} \mathrm{SO}_{4}\right)$ and concentrated in vacuo. The residue was purified by silica gel column chromatography and eluted with $\mathrm{CHCl}_{3} / \mathrm{MeOH}(20: 1$ 
with $\left.0.5 \% \mathrm{Et}_{3} \mathrm{~N}\right)$ to give compound $16(223 \mathrm{mg}, 89 \%)$ as a red foam. IR (KBr): $v 3323(\mathrm{NH}, \mathrm{OH})$, $1705(\mathrm{C}=\mathrm{O}), 1252(\mathrm{~N}=\mathrm{N}) \mathrm{cm}^{-1} ;[\alpha]_{\mathrm{D}}{ }^{24}-4.3$ (c 1.00, DMSO); ${ }^{1} \mathrm{H}-\mathrm{NMR}$ (500 MHz, DMSO-d6): $\delta 11.7$ $(1 \mathrm{H}, \mathrm{br} \mathrm{s}, \mathrm{NH}), 8.67(2 \mathrm{H}, \mathrm{d}, J=4.5 \mathrm{~Hz}), 8.05(1 \mathrm{H}, \mathrm{s}, \mathrm{H}-6), 7.68(2 \mathrm{H}, \mathrm{d}, J=8.5 \mathrm{~Hz}), 7.59(2 \mathrm{H}, \mathrm{d}$, $J=6.0 \mathrm{~Hz}), 7.28(2 \mathrm{H}, \mathrm{d}, J=7.0 \mathrm{~Hz}), 7.17-7.09(8 \mathrm{H}, \mathrm{m}), 7.02-7.00(1 \mathrm{H}, \mathrm{m}), 6.70-6.68(4 \mathrm{H}, \mathrm{m}), 6.01$ $\left(1 \mathrm{H}, \mathrm{t}, J=6.5 \mathrm{~Hz}, \mathrm{H}-1^{\prime}\right), 5.23-5.21(1 \mathrm{H}, \mathrm{m}, \mathrm{OH}), 4.19-4.17\left(1 \mathrm{H}, \mathrm{m}, \mathrm{H}-3{ }^{\prime}\right), 3.82\left(1 \mathrm{H}, \mathrm{s}, \mathrm{H}-4{ }^{\prime}\right), 3.49(6 \mathrm{H}$, s, OMe), 3.06-3.04 (2H, m, H-5'), 2.16-2.13 (2H, m, H-2'); ${ }^{13} \mathrm{C}-\mathrm{NMR}$ (125 MHz, DMSO- $\left.d 6\right): \delta 161.3$, 158.1, 156.5, 151.6, 150.7, 149.3, 144.7, 143.7, 135.5, 135.4, 132.2, 129.6, 127.9, 127.6, 126.7, 126.6, 123.1, 115.9, 113.2, 98.1, 86.1, 86.0, 85.8, 85.3, 70.35, 63.5, 54.96, 40.4; MALDI-TOF-HRMS m/z $\left(\mathrm{MH}^{+}\right)$calcd for $\mathrm{C}_{43} \mathrm{H}_{38} \mathrm{~N}_{5} \mathrm{O}_{7}: 736.2766$; found 736.2759 .

2.12. Preparation of 5'-O-(4,4'-dimethoxytrityl)-5-[4-(4-methoxyphenyl)diazenylphenyl] ethynyl-2'-deoxyuridine (17)

To a solution of compound $12(101 \mathrm{mg}, 0.218 \mathrm{mmol})$ in dry pyridine $(3 \mathrm{~mL})$ was added DMTrCl ( $89 \mathrm{mg}, 0.262 \mathrm{mmol}$ ) at room temperature, and the reaction mixture was stirred for $16 \mathrm{~h}$. The reaction was quenched by the addition of $\mathrm{MeOH}$ with 10 min stirring. The solvent was removed in vacuo, and the residue was partitioned between $\mathrm{CHCl}_{3}$ and $\mathrm{H}_{2} \mathrm{O}$. The separated organic layer was washed with $\mathrm{H}_{2} \mathrm{O}$, followed by brine. The organic layer was dried $\left(\mathrm{Na}_{2} \mathrm{SO}_{4}\right)$ and concentrated in vacuo. The residue was purified by silica gel column chromatography and eluted with $\mathrm{CHCl}_{3} / \mathrm{MeOH}(20: 1$ with $0.5 \%$ $\left.\mathrm{Et}_{3} \mathrm{~N}\right)$ to give compound $17(152 \mathrm{mg}, 90 \%)$ as an orange foam. IR $(\mathrm{KBr}): v 3437,3410(\mathrm{NH}, \mathrm{OH})$, $1701(\mathrm{C}=\mathrm{O}), 1272(\mathrm{~N}=\mathrm{N}) \mathrm{cm}^{-1} ;[\alpha]_{\mathrm{D}}{ }^{24} 28.4\left(\mathrm{c} 1.00, \mathrm{CHCl}_{3}\right) ;{ }^{1} \mathrm{H}-\mathrm{NMR}\left(500 \mathrm{MHz}, \mathrm{CDCl}_{3}\right): \delta 10.2(1 \mathrm{H}$, br s, NH), $8.28(1 \mathrm{H}, \mathrm{s}, \mathrm{H}-6), 7.88(2 \mathrm{H}, \mathrm{d}, J=7.0 \mathrm{~Hz}), 7.64(2 \mathrm{H}, \mathrm{d}, J=7.0 \mathrm{~Hz}), 7.46(2 \mathrm{H}, \mathrm{d}, J=7.0 \mathrm{~Hz})$, $7.36(4 \mathrm{H}, \mathrm{d}, J=7.5 \mathrm{~Hz}), 7.26-7.24(3 \mathrm{H}, \mathrm{m}), 7.11(1 \mathrm{H}, \mathrm{d}, J=8.0 \mathrm{~Hz}), 6.81-6.74(4 \mathrm{H}, \mathrm{m}), 6.45-6.37$ (1H, m, H-1'), 4.60-4.58 (1H, m, H-3'), 4.22-4.19 (1H, m, H-4'), 3.84 (3H, s), 3.49 (6H, s, OMe), 3.45 $\left(1 \mathrm{H}, \mathrm{d}, J=10.0 \mathrm{~Hz}, \mathrm{H}-5^{\prime}\right), 3.31(1 \mathrm{H}, \mathrm{d}, J=9.0 \mathrm{~Hz}, \mathrm{H}-5$ '), 2.68-2.57 (1H, m, H-2'), 2.40-2.28 (1H, m, H-2'), 1.29-1.19 (1H, m, OH); ${ }^{13} \mathrm{C}-\mathrm{NMR}\left(125 \mathrm{MHz}, \mathrm{CDCl}_{3}\right): \delta 162.1,161.8,158.4,151.6,149.5$, 146.9, 144.4, 135.5, 135.4, 132.3, 129.9, 129.8, 128.0, 127.8, 124.3, 122.1, 114.1, 113.2, 100.3, 93.5, 86.9, 86.0, 86.0, 82.2, 72.2, 60.3, 55.4, 55.0, 41.6; MALDI-TOF-HRMS $m / z\left(\mathrm{MH}^{+}\right)$calcd for $\mathrm{C}_{45} \mathrm{H}_{41} \mathrm{~N}_{4} \mathrm{O}_{8}: 765.2919$; found 765.2912.

\subsection{Preparation of 5'-O-(4,4'-dimethoxytrityl)-5-[4-(4-methylphenyl)diazenylphenyl]} ethynyl-2'-deoxyuridine (18)

To a solution of compound 13 (200 $\mathrm{mg}, 0.446 \mathrm{mmol})$ in dry pyridine $(5 \mathrm{~mL})$ was added DMTrCl (182 $\mathrm{mg}, 0.536 \mathrm{mmol}$ ) at room temperature, and the reaction mixture was stirred for $16 \mathrm{~h}$. The reaction was quenched by the addition of $\mathrm{MeOH}$ with $10 \mathrm{~min}$ stirring. The solvent was removed in vacuo, and the residue was partitioned between $\mathrm{CHCl}_{3}$ and $\mathrm{H}_{2} \mathrm{O}$. The separated organic layer was washed with $\mathrm{H}_{2} \mathrm{O}$, followed by brine. The organic layer was dried $\left(\mathrm{Na}_{2} \mathrm{SO}_{4}\right)$ and concentrated in vacuo. The residue was purified by silica gel column chromatography and eluted with hexane/AcOEt (1:2) to give compound $18(208 \mathrm{mg}, 62 \%)$ as an orange foam. IR (KBr): v $3425(\mathrm{NH}, \mathrm{OH}), 1707(\mathrm{C}=\mathrm{O})$, $1253(\mathrm{~N}=\mathrm{N}) \mathrm{cm}^{-1} ;[\alpha]_{\mathrm{D}^{24}}-27.9\left(\mathrm{c} 1.00, \mathrm{CHCl}_{3}\right) ;{ }^{1} \mathrm{H}-\mathrm{NMR}\left(500 \mathrm{MHz}, \mathrm{CDCl}_{3}\right): \delta 9.09(1 \mathrm{H}, \mathrm{br} \mathrm{s}, \mathrm{NH})$, $8.27(1 \mathrm{H}, \mathrm{s}, \mathrm{H}-6), 7.80(2 \mathrm{H}, \mathrm{d}, J=8.0 \mathrm{~Hz}), 7.67(2 \mathrm{H}, \mathrm{d}, J=7.5 \mathrm{~Hz}), 7.45(2 \mathrm{H}, \mathrm{d}, J=8.0 \mathrm{~Hz}), 7.35$ $(4 \mathrm{H}, \mathrm{d}, J=8.5 \mathrm{~Hz}), 7.31-7.24(4 \mathrm{H}, \mathrm{m}), 7.15(1 \mathrm{H}, \mathrm{t}, J=7.0 \mathrm{~Hz}), 7.11(2 \mathrm{H}, \mathrm{d}, J=8.5 \mathrm{~Hz}), 6.81-6.78$ 
$(4 \mathrm{H}, \mathrm{m}), 6.38\left(1 \mathrm{H}, \mathrm{t}, J=4.0 \mathrm{~Hz}, \mathrm{H}-1^{\prime}\right), 4.60-4.57\left(1 \mathrm{H}, \mathrm{m}, \mathrm{H}-3^{\prime}\right), 4.17-4.09$ (1H, m, H-4'), 3.77-3.65 (6H, m, OMe), 3.50-3.46 (1H, m, H-5'), 3.40-3.28 (1H, m, H-5'), 2.67-2.52 (2H, m, H-2'), 1.86-1.82 $(1 \mathrm{H}, \mathrm{m}, \mathrm{OH}) ;{ }^{13} \mathrm{C}-\mathrm{NMR}\left(125 \mathrm{MHz}, \mathrm{CDCl}_{3}\right): \delta 161.2,158.6,151.7,150.7,149.2,144.4,141.9,135.4$, 132.4, 130.0, 129.9, 129.8, 128.1, 127.9, 127.1, 124.7, 122.9, 122.3, 113.4, 100.4, 93.6, 87.1, 86.8, 85.9, 72.4, 63.5, 55.2, 41.2, 21.5; MALDI-TOF-HRMS $m / z\left(\mathrm{MNa}^{+}\right)$calcd for $\mathrm{C}_{45} \mathrm{H}_{40} \mathrm{~N}_{4} \mathrm{O}_{7} \mathrm{Na}$ : 771.2789 ; found 771.2780 .

\subsection{Preparation of 5'-O-(4,4'-dimethoxytrityl)-5-[4-(4-trifluoromethylphenyl)diazenylphenyl]} ethyn-yl-2'-deoxyuridine (19)

To a solution of compound $14(114 \mathrm{mg}, 0.228 \mathrm{mmol})$ in dry pyridine $(3 \mathrm{~mL})$ was added DMTrCl (93 $\mathrm{mg}, 0.273 \mathrm{mmol}$ ) at room temperature, and the reaction mixture was stirred for $16 \mathrm{~h}$. The reaction was quenched by the addition of $\mathrm{MeOH}$ with 10 min stirring. The solvent was removed in vacuo, and the residue was partitioned between $\mathrm{CHCl}_{3}$ and $\mathrm{H}_{2} \mathrm{O}$. The separated organic layer was washed with $\mathrm{H}_{2} \mathrm{O}$, followed by brine. The organic layer was dried $\left(\mathrm{Na}_{2} \mathrm{SO}_{4}\right)$ and concentrated in vacuo. The residue was purified by silica gel column chromatography and eluted with $\mathrm{CHCl}_{3}$ with $0.5 \% \mathrm{Et}_{3} \mathrm{~N}$ ) to give compound $19(118 \mathrm{mg}, 65 \%)$ as an orange foam. IR (KBr): v $3372(\mathrm{NH}, \mathrm{OH}), 1669(\mathrm{C}=\mathrm{O})$, $1253(\mathrm{~N}=\mathrm{N}) \mathrm{cm}^{-1} ;[\alpha]_{\mathrm{D}}{ }^{24} 26.9\left(\mathrm{c} 1.00, \mathrm{CHCl}_{3}\right) ;{ }^{1} \mathrm{H}-\mathrm{NMR}\left(300 \mathrm{MHz}, \mathrm{CDCl}_{3}\right): \delta 10.04(1 \mathrm{H}$, br s, NH), $8.25(1 \mathrm{H}, \mathrm{s}, \mathrm{H}-6), 7.85(2 \mathrm{H}, \mathrm{d}, J=8.5 \mathrm{~Hz}), 7.69-7.55(4 \mathrm{H}, \mathrm{m}), 7.41-7.12(8 \mathrm{H}, \mathrm{m}), 7.07-6.95(3 \mathrm{H}, \mathrm{m})$, 6.71-6.69 (4H, m), 6.36-6.29 (1H, m, H-1'), 4.55-4.47 (1H, m, H-3'), 4.15-4.07 (1H, m, H-4'), 3.57 (6H, s, OMe), 3.42-3.34 (1H, m, H-5'), 3.25-3.18 (1H, m, H-5'), 2.60-2.42 (2H, m, H-2'), 2.32-2.21 $(1 \mathrm{H}, \mathrm{m}), 0.99-0.90(1 \mathrm{H}, \mathrm{m}, \mathrm{OH}) ;{ }^{13} \mathrm{C}-\mathrm{NMR}\left(75 \mathrm{MHz}, \mathrm{CDCl}_{3}\right): \delta 161.7,158.5,154.2,151.2,149.5$, 135.5, 132.4, 129.88, 129.86, 128.0, 127.9, 127.0, 126.22, 126.18, 126.0, 125.9, 123.0, 122.7, 113.3, 100.2, 93.3, 87.0, 86.9, 86.1, 83.7, 83.1, 75.2, 72.3, 55.1, 24.7; MALDI-TOF-HRMS m/z $\left(\mathrm{MNa}^{+}\right)$calcd for $\mathrm{C}_{45} \mathrm{H}_{37} \mathrm{~N}_{4} \mathrm{O}_{7} \mathrm{~F}_{3} \mathrm{Na}$ : 825.2507; found 825.2497.

\subsection{Preparation of 5'-O-(4,4'-dimethoxytrityl)-5-[4-(4-nitrophenyl)diazenylphenyl] ethynyl-2'-deoxyuridine (20)}

To a solution of compound $15(150 \mathrm{mg}, 0.314 \mathrm{mmol})$ in dry pyridine $(3 \mathrm{~mL})$ was added DMTrCl $(128 \mathrm{mg}, 0.377 \mathrm{mmol})$ at room temperature, and the reaction mixture was stirred for $16 \mathrm{~h}$. The reaction was quenched by the addition of $\mathrm{MeOH}$ with $10 \mathrm{~min}$ stirring. The solvent was removed in vacuo, and the residue was partitioned between $\mathrm{CHCl}_{3}$ and $\mathrm{H}_{2} \mathrm{O}$. The separated organic layer was washed with $\mathrm{H}_{2} \mathrm{O}$, followed by brine. The organic layer was dried $\left(\mathrm{Na}_{2} \mathrm{SO}_{4}\right)$ and concentrated in vacuo. The residue was purified by silica gel column chromatography and eluted with $\mathrm{CHCl}_{3} / \mathrm{MeOH}(20: 1$ with $\left.0.5 \% \mathrm{Et}_{3} \mathrm{~N}\right)$ to give compound $20(115 \mathrm{mg}, 47 \%)$ as a red foam. IR (KBr): $v 3452(\mathrm{NH}, \mathrm{OH})$, $1703(\mathrm{C}=\mathrm{O}), 1251(\mathrm{~N}=\mathrm{N}) \mathrm{cm}^{-1} ;[\alpha]_{\mathrm{D}^{24}}-16.9\left(\mathrm{c} 1.00, \mathrm{CHCl}_{3}\right) ;{ }^{1} \mathrm{H}-\mathrm{NMR}\left(500 \mathrm{MHz}, \mathrm{CDCl}_{3}\right): \delta 9.98(1 \mathrm{H}$, br s, NH), 8.38-8.22 (3H, m), $7.95(2 \mathrm{H}, \mathrm{d}, J=7.0 \mathrm{~Hz}), 7.69(2 \mathrm{H}, \mathrm{d}, J=7.0 \mathrm{~Hz}), 7.49-7.14(8 \mathrm{H}, \mathrm{m})$, $7.06(2 \mathrm{H}, \mathrm{d}, J=7.0 \mathrm{~Hz}), 6.83-6.72(5 \mathrm{H}, \mathrm{m}), 6.43-6.38\left(1 \mathrm{H}, \mathrm{m}, \mathrm{H}-1^{\prime}\right), 4.61-4.57\left(1 \mathrm{H}, \mathrm{m}, \mathrm{H}-3^{\prime}\right)$, 4.21-4.16 (1H, m, H-4'), 3.65 (6H, s, OMe), 3.50-3.45 (1H, m, H-5'), 3.33-3.26 (1H, m, H-5'), 2.66-2.59 (1H, m, H-2'), 2.34-2.27 (1H, m, H-2'), 1.28-1.17 (1H, m, OH); ${ }^{13} \mathrm{C}-\mathrm{NMR}(125 \mathrm{MHz}$, $\left.\mathrm{CDCl}_{3}\right): \delta 161.6,158.5,155.5,151.2,148.6,144.4,135.5,135.4,132.4,132.3,129.9,128.0,127.9$, 
127.8, 127.0, 124.6, 124.5, 123.4, 123.3, 123.0, 122.9, 113.3, 113.2, 100.1, 87.0, 86.9, 72.2, 55.1; MALDI-TOF-HRMS $m / z\left(\mathrm{MNa}^{+}\right)$calcd for $\mathrm{C}_{44} \mathrm{H}_{37} \mathrm{~N}_{5} \mathrm{O} 9 \mathrm{Na}$ : 802.2483; found 802.2501.

2.16. Preparation of 3'-O-[2-cyanoethyl(diisopropylamino)phosphino]-5'-O-(4,4'-dimethoxytrityl)-5[4-(4-pyridyl)diazenylphenyl]ethynyl-2'-deoxyuridine (21)

Under an argon atmosphere, to a solution of compound 16 (223 mg, $0.312 \mathrm{mmol}$ ) in dry $\mathrm{CH}_{2} \mathrm{Cl}_{2}$ (3 $\mathrm{mL})$ was added $N, N$-diisopropylamine $(160 \mu \mathrm{L}, 0.935 \mathrm{mmol})$ and 2-cyanoethyl- $N, N^{\prime}$ diisopropylchlorophosphoramidite $(105 \mu \mathrm{L}, 0.468 \mathrm{mmol})$ at room temperature, and the reaction mixture was stirred for $3 \mathrm{~h}$. The resultant mixture was partitioned between AcOEt and $\mathrm{H}_{2} \mathrm{O}$. The separated organic layer was washed with saturated aqueous $\mathrm{NaHCO}_{3}$, followed by brine. The organic layer was dried $\left(\mathrm{Na}_{2} \mathrm{SO}_{4}\right)$ and concentrated in vacuo. The residue was purified by silica gel column chromatography and eluted with $\mathrm{CHCl}_{3} / \mathrm{MeOH}\left(20: 1\right.$ with $\left.0.5 \% \mathrm{Et}_{3} \mathrm{~N}\right)$ to give a 1:1 diastereomeric mixture of 21 $(219 \mathrm{mg}, 75 \%)$ as a red foam. IR $(\mathrm{KBr}): v 3603(\mathrm{NH}), 1712(\mathrm{C}=\mathrm{O}), 1251(\mathrm{~N}=\mathrm{N}) \mathrm{cm}^{-1} ;[\alpha]_{\mathrm{D}}{ }^{24} 32.3$ (c 1.00, $\left.\mathrm{CHCl}_{3}\right)$; ${ }^{1} \mathrm{H}-\mathrm{NMR}\left(300 \mathrm{MHz}, \mathrm{CDCl}_{3}\right): \delta 8.84(2 \mathrm{H}, \mathrm{m}), 8.42(0.3 \mathrm{H}, \mathrm{s}, \mathrm{H}-6), 8.37(0.7 \mathrm{H}, \mathrm{s}, \mathrm{H}-6)$, 7.74-7.70 (4H, m), 7.51-7.50 (2H, m), 7.41-7.35 (4H, m), 7.31-7.16 (3H, m), 7.04 (2H, dd, $J=9.0$, $8.5 \mathrm{~Hz}), 6.83-6.77$ (4H, m), 6.42-6.36 (1H, m, H-1'), 4.72-4.61 (1H, m, H-3'), 4.27-4.19 (1H, m, H-5'), 3.93-3.74 (1H, m, H-5'), 3.71 (6H, s, OMe), 3.67-3.49 (4H, m, $\left.\mathrm{CH}_{2} \mathrm{CH}_{2} \mathrm{CN}\right), 3.36-3.24$ (1H, m, H-4'), 2.72-2.52 (2H, m, H-2'), 2.49-2.35 (2H, m), $1.28\left(8.4 \mathrm{H}, \mathrm{t}, \mathrm{J}=7.0 \mathrm{~Hz},\left((\mathrm{CH})_{2} \mathrm{CH}\right)_{2} \mathrm{~N}\right), 1.17(3.6 \mathrm{H}, \mathrm{t}$, $\left.J=7.0 \mathrm{~Hz},\left(\left(\mathrm{CH}_{3}\right)_{2} \mathrm{CH}\right)_{2} \mathrm{~N}\right) ;{ }^{13} \mathrm{C}-\mathrm{NMR}\left(125 \mathrm{MHz} \mathrm{CDCl}_{3}\right): \delta 158.5,157.1,151.1,144.33,144.29$, $132.8,135.5,135.4,135.3,132.4,132.3,129.9,128.0,127.9,127.8,127.0,126.8,122.91,122.89$, $117.5,116.2,113.2,100.1,93.0,87.0,85.8,63.1,58.4,58.2,58.1,57.9,55.1,43.23,43.17,43.07$, 43.01, 40.9, 24.6, 24.54, 24.48, 24.44, 24.39, 21.5, 20.4, 20.3, 20.2; ${ }^{31} \mathrm{P}-\mathrm{NMR}\left(120 \mathrm{MHz}, \mathrm{CDCl}_{3}\right)$ : $\delta$ 148.8, 148.4; MALDI-TOF-HRMS $m / z\left(\mathrm{MNa}^{+}\right)$calcd for $\mathrm{C}_{22} \mathrm{H}_{54} \mathrm{~N}_{7} \mathrm{O}_{8} \mathrm{NaP}$ : 958.3664; found 958.3647.

2.17. Preparation of 3'-O-[2-cyanoethyl(diisopropylamino)phosphino]-5'-O-(4,4'-dimethoxytrityl)-5[4-(4-methoxyphenyl)diazenylphenyl]ethynyl-2'-deoxyuridine (22)

Under an argon atmosphere, to a solution of compound 17 (152 mg, $0.199 \mathrm{mmol}$ ) in dry $\mathrm{CH}_{2} \mathrm{Cl}_{2}$ $(2 \mathrm{~mL})$ was added $N, N$-diisopropylamine $(103 \mu \mathrm{L}, 0.600 \mathrm{mmol})$ and 2-cyanoethyl- $N, N^{\prime}$ diisopropylchlorophosphoramidite $(67 \mu \mathrm{L}, 0.299 \mathrm{mmol})$ at room temperature, and the reaction mixture was stirred for $3 \mathrm{~h}$. The resultant mixture was partitioned between AcOEt and $\mathrm{H}_{2} \mathrm{O}$. The separated organic layer was washed with saturated aqueous $\mathrm{NaHCO}_{3}$, followed by brine. The organic layer was dried $\left(\mathrm{Na}_{2} \mathrm{SO}_{4}\right)$ and concentrated in vacuo. The residue was purified by silica gel column chromatography and eluted with $\mathrm{CHCl}_{3} / \mathrm{MeOH}\left(20: 1\right.$ with $\left.0.5 \% \mathrm{Et}_{3} \mathrm{~N}\right)$ to give a $3: 1$ diastereomeric mixture of $22(72 \mathrm{mg}, 38 \%)$ as an orange foam. IR (KBr): $v 3624(\mathrm{NH}), 1700(\mathrm{C}=\mathrm{O})$, $1253(\mathrm{~N}=\mathrm{N}) \mathrm{cm}^{-1} ;[\alpha]_{\mathrm{D}}{ }^{24} 19.4\left(\mathrm{c} 1.00, \mathrm{CHCl}_{3}\right) ;{ }^{1} \mathrm{H}-\mathrm{NMR}\left(500 \mathrm{MHz}, \mathrm{CDCl}_{3}\right): \delta 9.76(1 \mathrm{H}$, br s, NH), 8.37-8.28 (1H, m, H-6), $7.89(2 \mathrm{H}, \mathrm{d}, J=7.5 \mathrm{~Hz}), 7.66(2 \mathrm{H}, \mathrm{t}, J=8.0 \mathrm{~Hz}), 7.51-7.47(2 \mathrm{H}, \mathrm{m})$, 7.41-7.31 (4H, m), 7.31-7.25 (2H, m), 7.19-7.12 (1H, m), 7.08 (2H, dd, J = 6.0, 10.0 Hz), 7.01-6.96 (2H, m), 6.84-6.78 (4H, m), 6.41-6.31 (1H, m, H-1'), 4.70-4.62 (1H, m, H-3'), 4.31-4.29 (0.25H, m, H-4'), 4-18-416 (0.75H, m, H-4'), 3.87-3.82 (4H, m, $\left.\mathrm{CH}_{2} \mathrm{CH}_{2} \mathrm{CN}\right), 3.82$ (3H, s), 3.68 (6H, s, OMe), 3.64-3.48 $\left(2 \mathrm{H}, \mathrm{m}, \mathrm{H}-5^{\prime}\right), 2.76-2.58\left(2 \mathrm{H}, \mathrm{m}, \mathrm{H}-2^{\prime}\right), 2.47-2.35\left(2 \mathrm{H}, \mathrm{m},\left(\left(\mathrm{CH}_{3}\right)_{2} \mathrm{CH}\right)_{2} \mathrm{~N}\right), 1.28(9 \mathrm{H}, \mathrm{t}, J=7.0 \mathrm{~Hz}$, $\left.\left(\left(\mathrm{CH}_{3}\right)_{2} \mathrm{CH}\right)_{2} \mathrm{~N}\right), 1.17\left(3 \mathrm{H}, \mathrm{t}, J=7.0 \mathrm{~Hz},\left(\left(\mathrm{CH}_{3}\right)_{2} \mathrm{CH}\right)_{2} \mathrm{~N}\right) ;{ }^{13} \mathrm{C}-\mathrm{NMR}\left(125 \mathrm{MHz}, \mathrm{CDCl}_{3}\right): \delta 162.0,158.4$, 
$151.6,149.2,146.8,144.2,144.2,135.28,135.25,132.18,132.17,129.8,129.78,129.75,127.9$, $127.85,127.82,127.7,126.9,124.6,124.3,121.97,121.95,117.3,114.1,113.2,100.2,100.1,93.3$, $86.8(\mathrm{~d}, J(\mathrm{C}, \mathrm{P})=3.5 \mathrm{~Hz}), 77.2,77.0,76.7,63.0,62.9,58.2,58.1,55.4,54.9,44.9(\mathrm{~d}, J(\mathrm{C}, \mathrm{P})=5.0 \mathrm{~Hz})$, 24.4, 24.3, 22.8, 22.7, $20.2(\mathrm{~d}, J(\mathrm{C}, \mathrm{P})=7.0 \mathrm{~Hz}) ;{ }^{31} \mathrm{P}-\mathrm{NMR}\left(200 \mathrm{MHz}, \mathrm{CDCl}_{3}\right): \delta 149.5,149.1$; MALDI-TOF-HRMS $m / z\left(\mathrm{MNa}^{+}\right)$calcd for $\mathrm{C}_{54} \mathrm{H}_{57} \mathrm{~N}_{6} \mathrm{O} 9 \mathrm{NaP}: 987.3817$; found 987.3826.

2.18. Preparation of 3'-O-[2-cyanoethyl(diisopropylamino)phosphino]-5'-O-(4,4'-dimethoxytrityl)-5[4-(4-methylphenyl)diazenylphenyl]ethynyl-2'-deoxyuridine (23)

Under an argon atmosphere, to a solution of compound 18 (170 mg, $0.227 \mathrm{mmol})$ in dry $\mathrm{CH}_{2} \mathrm{Cl}_{2}$ (3 $\mathrm{mL})$ was added $N, N$-diisopropylamine $(119 \mu \mathrm{L}, 0.681 \mathrm{mmol})$ and 2-cyanoethyl- $N, N^{\prime}$ diisopropylchlorophosphoramidite $(78 \mu \mathrm{L}, 0.341 \mathrm{mmol})$ at room temperature, and the reaction mixture was stirred for $3 \mathrm{~h}$. The resultant mixture was partitioned between AcOEt and $\mathrm{H}_{2} \mathrm{O}$. The separated organic layer was washed with saturated aqueous $\mathrm{NaHCO}_{3}$, followed by brine. The organic layer was dried $\left(\mathrm{Na}_{2} \mathrm{SO}_{4}\right)$ and concentrated in vacuo. The residue was purified by silica gel column chromatography and eluted with hexane/AcOEt (1:1) to give a 2:1 diastereomeric mixture of 23 $(120 \mathrm{mg}, 55 \%)$ as an orange foam. IR (KBr): $v 3610(\mathrm{NH}), 1699(\mathrm{C}=\mathrm{O}), 1272(\mathrm{~N}=\mathrm{N}) \mathrm{cm}^{-1} ;[\alpha]_{\mathrm{D}}^{24} 29.6$ (c 1.00, $\left.\mathrm{CHCl}_{3}\right) ;{ }^{1} \mathrm{H}-\mathrm{NMR}\left(500 \mathrm{MHz}, \mathrm{CDCl}_{3}\right): \delta 9.74(1 \mathrm{H}$, br s, NH), 8.35-8.26 (1H, m, H-6), 7.84-7.77 (2H, m), 7.71-7.63 (2H, m), 7.51-7.44 (2H, m), 7.41-7.33 (4H, m), 7.32-7.25 (5H, m), 7.12-7.03 (2H, m), 6.84-6.75 (4H, m), 6.41-6.31 (1H, m, H-1'), 4.72-4.60 (1H, m, H-3'), 4.29-4.19 (1H, m, H-4'), 3.93-3.74 (4H, m, $\left.\mathrm{CH}_{2} \mathrm{CH}_{2} \mathrm{CN}\right), 3.70$ (4H, s, OMe), 3.63 (2H, s, OMe), 3.37-3.12 (2H, m, H-5'), 2.72-2.50 (2H, m, H-2'), $2.50(3 \mathrm{H}, \mathrm{s}), 2.41-2.26\left(2 \mathrm{H}, \mathrm{m},\left(\left(\mathrm{CH}_{3}\right)_{2} \mathrm{CH}\right)_{2} \mathrm{~N}\right), 1.22-1.14(8 \mathrm{H}, \mathrm{m}$, $\left.\left(\left(\mathrm{CH}_{3}\right)_{2} \mathrm{CH}\right)_{2} \mathrm{~N}\right), 1.12-1.06\left(4 \mathrm{H}, \mathrm{m},\left(\left(\mathrm{CH}_{3}\right)_{2} \mathrm{CH}\right)_{2} \mathrm{~N}\right) ;{ }^{13} \mathrm{C}-\mathrm{NMR}\left(125 \mathrm{MHz}, \mathrm{CDCl}_{3}\right): \delta 153.6,146.7$, $145.7,139.3,137.4,136.8,130.4,127.4,124.93,124.91,124.74,124.72,123.0,122.9,122.0,121.9$, $119.8,117.9,119.3,112.5,108.3,88.5,82.1,80.9(\mathrm{~d}, J(\mathrm{C}, \mathrm{P})=3.5 \mathrm{~Hz}), 68.8,68.7,58.2,53.4,53.3,50.2$, 48.4, 38.2, 35.9, 35.8, $19.5(\mathrm{~d}, J(\mathrm{C}, \mathrm{P})=7.0 \mathrm{~Hz}), 16.5,15.4,15.3 ;{ }^{31} \mathrm{P}-\mathrm{NMR}\left(200 \mathrm{MHz}, \mathrm{CDCl}_{3}\right): \delta 149.6$, 149.2; MALDI-TOF-HRMS $m / z\left(\mathrm{MNa}^{+}\right)$calcd for $\mathrm{C}_{54} \mathrm{H}_{57} \mathrm{~N}_{6} \mathrm{O}_{8} \mathrm{NaP}$ : 971.3868; found 971.3875.

2.19. Preparation of 3'-O-[2-cyanoethyl(diisopropylamino)phosphino]-5'-O-(4,4'-dimethoxytrityl)-5[4-(4-trifluoromethylphenyl)diazenylphenyl]ethynyl-2'-deoxyuridine (24)

Under an argon atmosphere, to a solution of compound 19 (98 mg, $0.122 \mathrm{mmol})$ in dry $\mathrm{CH}_{2} \mathrm{Cl}_{2}$ $(2 \mathrm{~mL})$ was added $N, N$-diisopropylamine $(63 \mu \mathrm{L}, 0.366 \mathrm{mmol})$ and 2-cyanoethyl- $N, N^{\prime}$ diisopropylchlorophosphoramidite $(41 \mu \mathrm{L}, 0.183 \mathrm{mmol})$ at room temperature, and the reaction mixture was stirred for $3 \mathrm{~h}$. The resultant mixture was partitioned between AcOEt and $\mathrm{H}_{2} \mathrm{O}$. The separated organic layer was washed with saturated aqueous $\mathrm{NaHCO}_{3}$, followed by brine. The organic layer was dried $\left(\mathrm{Na}_{2} \mathrm{SO}_{4}\right)$ and concentrated in vacuo. The residue was purified by silica gel column chromatography and eluted with $\mathrm{CHCl}_{3} / \mathrm{MeOH}\left(20: 1\right.$ with $\left.0.5 \% \mathrm{Et}_{3} \mathrm{~N}\right)$ to give a $1: 1$ diastereomeric mixture of $24(106 \mathrm{mg}, 87 \%)$ as an orange foam. IR (KBr): $v 3640(\mathrm{NH}), 1674(\mathrm{C}=\mathrm{O})$, $1251(\mathrm{~N}=\mathrm{N}) \mathrm{cm}^{-1} ;[\alpha]_{\mathrm{D}}{ }^{24} 32.3\left(\mathrm{c} 1.00, \mathrm{CHCl}_{3}\right) ;{ }^{1} \mathrm{H}-\mathrm{NMR}\left(300 \mathrm{MHz}, \mathrm{CDCl}_{3}\right): \delta 8.39(0.4 \mathrm{H}, \mathrm{s}, \mathrm{H}-6)$, $8.34(0.6 \mathrm{H}, \mathrm{s}, \mathrm{H}-6), 8.01-7.95(2 \mathrm{H}, \mathrm{m}), 7.81-7.68(4 \mathrm{H}, \mathrm{m}), 7.51-7.45(2 \mathrm{H}, \mathrm{m}), 7.41-7.32(4 \mathrm{H}, \mathrm{m})$, 7.21-7.13 (1H, m), 7.09-6.99 (2H, m), 6.85-6.75 (6H, m), 6.42-6.31 (1H, m, H-1'), 4.70-4.59 (1H, m, H-3'), 4.29-4.15 (1H, m, H-4'), 3.75-3.64 (4H, m, $\left.\mathrm{CH}_{2} \mathrm{CH}_{2} \mathrm{CN}\right), 3.48$ (6H, s, OMe), 3.43-3.18 (2H, m, 
H-5'), 2.70-2.60 (2H, m, H-2'), 2.50-2.33 (2H, m, $\left.\left(\left(\mathrm{CH}_{3}\right)_{2} \mathrm{CH}\right)_{2} \mathrm{~N}\right), 1.21-1.14\left(7.2 \mathrm{H}, \mathrm{m},\left((\mathrm{CH})_{2} \mathrm{CH}\right)_{2} \mathrm{~N}\right)$, 1.10-1.04 (4.8H, m, $\left.\left(\left(\mathrm{CH}_{3}\right)_{2} \mathrm{CH}\right)_{2} \mathrm{~N}\right) ;{ }^{13} \mathrm{C}-\mathrm{NMR}\left(125 \mathrm{MHz}, \mathrm{CDCl}_{3}\right): \delta 161.2,158.6,154.3,151.3,149.1$, $146.9,144.4,144.3,142.7,135.5,135.4,132.4,132.3,32.0,129.97,129.92,129.7,128.0,127.9,127.8$, 127.0, 126.3, 126.2, 126.0, 125.9, 125.6, 123.0, 122.7, 120.3, 117.6, 117.4, 116.7, 113.3, 100.4, 100.2, 93.2, 87.2, 87.0, 86.3, 85.9, 85.8, 83.0, 77.4, 77.2, 77.0, 76.6, 75.0, 74.9, 73.7, 63.1, 58.4, 58.2, 58.1, 55.2, 55.4, 53.4, 50.7, 43.3, 43.2, 43.1, 43.0, 40.8, 24.8, 24.6, 24.56, 24.51, 24.47, 24.41, 22.8, 20.4, 20.3, 20.1; ${ }^{31} \mathrm{P}-\mathrm{NMR}\left(120 \mathrm{MHz}, \mathrm{CDCl}_{3}\right): \delta 148.9,148.4$; MALDI-TOF-HRMS $\mathrm{m} / \mathrm{z}\left(\mathrm{MNa}^{+}\right)$calcd for $\mathrm{C}_{54} \mathrm{H}_{54} \mathrm{~N}_{6} \mathrm{O}_{8} \mathrm{~F}_{3} \mathrm{NaP}: 1025.3585$; found 1025.3596.

2.20. Preparation of 3'-O-[2-cyanoethyl(diisopropylamino)phosphino]-5'-O-(4,4'-dimethoxytrityl)-5[4-(4-nitrophenyl)diazenylphenyl] ethynyl-2'-deoxyuridine (25)

Under an argon atmosphere, to a solution of compound 20 (111 mg, $0.142 \mathrm{mmol}$ ) in dry $\mathrm{CH}_{2} \mathrm{Cl}_{2}$ (2 $\mathrm{mL})$ was added $N, N$-diisopropylamine $(74 \mu \mathrm{L}, 0.426 \mathrm{mmol})$ and 2-cyanoethyl- $N, N^{\prime}$ diisopropylchlorophosphoramidite $(48 \mu \mathrm{L}, 0.213 \mathrm{mmol})$ at room temperature, and the reaction mixture was stirred for $3 \mathrm{~h}$. The resultant mixture was partitioned between AcOEt and $\mathrm{H}_{2} \mathrm{O}$. The separated organic layer was washed with saturated aqueous $\mathrm{NaHCO}_{3}$, followed by brine. The organic layer was dried $\left(\mathrm{Na}_{2} \mathrm{SO}_{4}\right)$ and concentrated in vacuo. The residue was purified by silica gel column chromatography and eluted with $\mathrm{CHCl}_{3} / \mathrm{MeOH}\left(20: 1\right.$ with $\left.0.5 \% \mathrm{Et}_{3} \mathrm{~N}\right)$ to give a $2: 1$ diastereomeric mixture of $25(137 \mathrm{mg}, 99 \%)$ as a red foam. IR (KBr): $v 3576(\mathrm{NH}), 1712(\mathrm{C}=\mathrm{O}), 1252$ $(\mathrm{N}=\mathrm{N}) \mathrm{cm}^{-1} ;[\alpha]_{\mathrm{D}}{ }^{24}-15.0\left(\mathrm{c} 1.00, \mathrm{CHCl}_{3}\right) ;{ }^{1} \mathrm{H}-\mathrm{NMR}\left(500 \mathrm{MHz}, \mathrm{CDCl}_{3}\right): \delta 9.45(1 \mathrm{H}$, br s, NH), 8.45-8.29 (3H, m), 8.04-7.99 (2H, m), 7.76-7.70 (2H, m), 7.53-7.47 (2H, m), 7.42-7.36 (4H, m), 7.31-7.26 (2H, m), 7.20-7.14 (1H, m), 7.11-7.03 (2H, m), 6.85-6.79 (4H, m), 6.42-6.35 (1H, m, H-1'), 4.71-4.63 (1H, m, H-4'), 4.30-4.25 (0.33H, m, H-3'), 4.24-4.20 (0.67H, m, H-3'), 3.89-3.75 (4H, m, $\mathrm{CH}_{2} \mathrm{CH}_{2} \mathrm{CN}$ ), 3.72-3.69 (6H, m, OMe), 3.65-3.50 (2H, m, H-5'), 2.75-2.61 (2H, m, H-2'), 2.47-2.35 $\left(2 \mathrm{H}, \mathrm{m},\left(\left(\mathrm{CH}_{3}\right)_{2} \mathrm{CH}\right)_{2} \mathrm{~N}\right), 1.22-1.16\left(8 \mathrm{H}, \mathrm{m},\left(\left(\mathrm{CH}_{3}\right)_{2} \mathrm{CH}\right)_{2} \mathrm{~N}\right), 1.16-1.06\left(4 \mathrm{H}, \mathrm{m},\left(\left(\mathrm{CH}_{3}\right)_{2} \mathrm{CH}\right)_{2} \mathrm{~N}\right)$; ${ }^{13} \mathrm{C}-\mathrm{NMR}\left(125 \mathrm{MHz}, \mathrm{CDCl}_{3}\right): \delta 156.5,153.3,150.6,146.2,144.3,143.7,139.4,137.8,130.5,127.5,124.9$, 123.0, 122.9, 122.0, 121.8, 119.7, 119.53, 119.52, 118.0, 112.6, 103.3, 93.2, $81.9(\mathrm{~d}, J(\mathrm{C}, \mathrm{P})=3.5 \mathrm{~Hz})$, 68.7, 68.4, 62.9, 62.8, 58.1, 58.0, 55.4, 54.9, $38.9(\mathrm{~d}, J(\mathrm{C}, \mathrm{P})=5.0 \mathrm{~Hz}), 24.4,24.3,22.8,22.7,19.5(\mathrm{~d}$, $J(\mathrm{C}, \mathrm{P})=7.0 \mathrm{~Hz}) ;{ }^{31} \mathrm{P}-\mathrm{NMR}\left(200 \mathrm{MHz}, \mathrm{CDCl}_{3}\right): \delta$ 149.6, 149.3; MALDI-TOF-HRMS $\mathrm{m} / \mathrm{z}\left(\mathrm{MNa}^{+}\right)$ calcd for $\mathrm{C}_{53} \mathrm{H}_{54} \mathrm{~N}_{7} \mathrm{O}_{10} \mathrm{NaP}: 1002.3567$; found 1002.3570 .

\subsection{Synthesis of $\boldsymbol{d} \boldsymbol{U}^{A z}$-Modified Oligodeoxynucleotides}

Solid-phase oligonucleotide synthesis was performed using commercially available reagents and phosphoramidites with activator 42 (Sigma-Aldrich) as the activator. para-Substituted-dU ${ }^{\mathbf{A z}}$ phosphoramidites were chemically synthesized as described above. All of the reagents were assembled, and the ONs were synthesized according to the standard synthesis cycle (trityl on mode). Cleavage from the solid support and deprotection were accomplished with concentrated ammonium hydroxide solution at $55{ }^{\circ} \mathrm{C}$ for $12 \mathrm{~h}$. The crude oligonucleotides were purified with Sep-Pak Plus C18 cartridges (Waters, MA, USA) followed by RP-HPLC on a XBridge ${ }^{\mathrm{TM}}$ OST C18 column, $2.5 \mu \mathrm{m}, 10 \times 50 \mathrm{~mm}$ (Waters) using $\mathrm{MeCN}$ in $0.1 \mathrm{M}$ triethylammonium acetate buffer ( $\mathrm{pH} 7.0$ ). The purified oligonucleotides were quantified by UV absorbance at $260 \mathrm{~nm}$ and confirmed by MALDI-TOF mass spectrometry (Table 1). 
Table 1. Yields and MALDI-TOF MS data of $\mathbf{d U}^{\mathbf{A z}}$-modified ONs.

\begin{tabular}{|c|c|c|c|c|}
\hline \multirow{2}{*}{$\mathrm{ON}^{a}$} & \multirow{2}{*}{$\mathbf{X}$} & \multirow{2}{*}{ Yield/\% } & \multicolumn{2}{|c|}{ MALDI-TOF MS } \\
\hline & & & Calcd. $[\mathrm{M}-\mathrm{H}]^{-}$ & Found $[\mathrm{M}-\mathrm{H}]$ \\
\hline 28 & $\mathrm{dU}^{\mathrm{Az}}$-OMe & 21 & 3852.6 & 3853.2 \\
\hline 29 & $\mathrm{dU}^{\mathrm{Az}}-\mathrm{Me}$ & 27 & 3836.6 & 3836.2 \\
\hline 30 & $\mathrm{dU}^{\mathrm{Az}}-\mathrm{CF}_{\mathbf{3}}$ & 15 & 3890.6 & 3890.2 \\
\hline 31 & $\mathrm{dU}^{\mathrm{Az}}-\mathrm{NO}_{2}$ & 22 & 3866.6 & 3866.9 \\
\hline 32 & dU $U^{A z}$-pyridyl & 21 & 3823.6 & 3824.2 \\
\hline
\end{tabular}

\subsection{UV Melting Experiments}

Equimolecular amounts of the target DNA/RNA and ONs were dissolved in $10 \mathrm{mM}$ sodium phosphate buffer ( $\mathrm{pH} 7.0$ ) containing $100 \mathrm{mM} \mathrm{NaCl}$ to give a final strand concentration of $4.0 \mu \mathrm{M}$. The melting samples were denatured at $100{ }^{\circ} \mathrm{C}$ and annealed slowly to room temperature. Absorbance was recorded in the forward and reverse directions at temperatures of $5-90{ }^{\circ} \mathrm{C}$ at a rate of $0.5^{\circ} \mathrm{C} / \mathrm{min}$.

\subsection{Photo-Isomerization of $\boldsymbol{d} \boldsymbol{U}^{A z}$ Analogues}

ONs were dissolved in a $10 \mathrm{mM}$ sodium phosphate buffer (pH 7.0) containing $100 \mathrm{mM} \mathrm{NaCl}$ to give a final strand concentration of $4.0 \mu \mathrm{M}$. The $\mathrm{ON}$ solution was exposed to the appropriate wavelength of monochromic light for 10 seconds and subsequently analyzed by RP-HPLC. The ratio of cis/trans isomers was obtained from the HPLC peak areas at $260 \mathrm{~nm}$.

\subsection{Thermal Isomerization of cis-d $\boldsymbol{U}^{A z}$ Analogues}

ONs were dissolved in $10 \mathrm{mM}$ sodium phosphate buffer ( $\mathrm{pH} 7.0$ ) containing $100 \mathrm{mM} \mathrm{NaCl}$ to give a final strand concentration of $4.0 \mu \mathrm{M}$. The oligonucleotide solution was exposed to the appropriate wavelength of monochromic light for 10 seconds and subsequently heated to $60{ }^{\circ} \mathrm{C}$. The change of absorbance at $365 \mathrm{~nm}$ or $400 \mathrm{~nm}$ was monitored by a UV-Vis spectrophotometer and plotted to calculate the half-life time of $c i s-\mathbf{d} \mathbf{U}^{\mathbf{A z}}$ analogues.

\subsection{Isothermal Titration Calorimetry}

Prior to experiments, all solutions (titrant and titrand) were denatured at $100{ }^{\circ} \mathrm{C}$ and annealed slowly to room temperature. Titrations were carried out by injecting $2 \mu \mathrm{L}$ portions of the complementary RNA strand into $250 \mu \mathrm{L}$ of the $\mathbf{d U}^{\mathrm{Az}}$-modified $\mathrm{ON}$ solution in the calorimetric cell. The $\mathbf{d U}^{\mathrm{Az}}$-modified $\mathrm{ON}$ concentrations in the cell were $0.1 \mu \mathrm{M}$, and the solutions in the syringe were $1 \mu \mathrm{M}$. The equilibration period after each injection was $360 \mathrm{~s}$. The measurements were performed with and without the photo-isomerization of $\mathbf{d} \mathbf{U}^{\mathrm{Az}}$-modified ONs. 


\section{Results}

\subsection{Synthesis of Para-Substituted $\mathbf{d U}^{\text {Az }}$ Phosphoramidites and Modified Oligonucleotides}

The synthetic route for para-substituted ethynyl-azobenzene derivatives is outlined in Scheme 1. 4-4-[(Trimethylsilyl)ethynylphenylazo]pyridine $\mathbf{2}$ was synthesized from the prepared 4-(4-iodophenylazo)pyridine 1 [18] through a palladium-catalyzed cross-coupling reaction [22] with trimethylsilylacetylene. TMS-protected ethynyl-azobenzene derivatives 2-4 [19] were converted to compounds 5-7 by removal of the silyl group. Compounds 8 and $\mathbf{9}$ were also synthesized according to the reported procedures $[20,21]$.

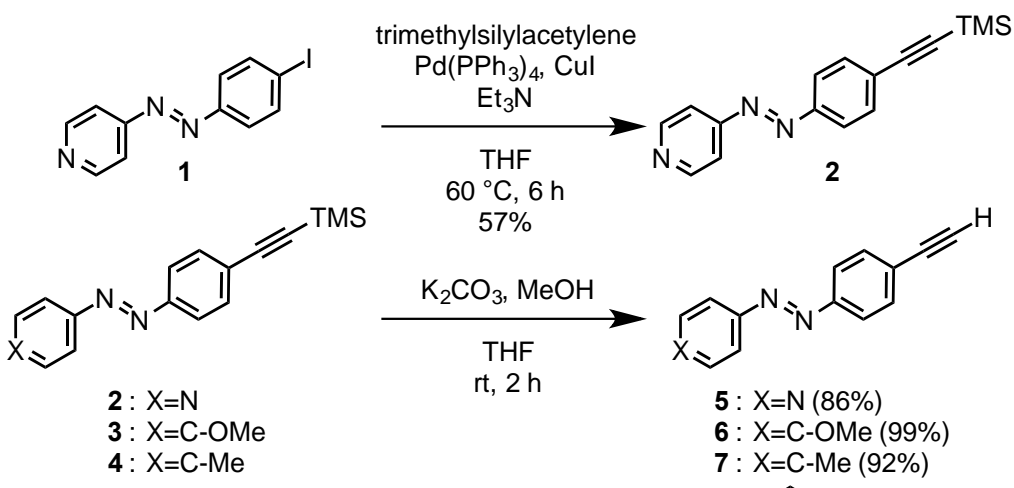

Scheme 1. Route for the synthesis of para-substituted ethynyl-azobenzene derivatives.

The preparation of para-substituted $\mathbf{d} \mathbf{U}^{\mathbf{A z}}$ phosphoramidites commenced with the coupling of 4-ethynyl-azobenzene derivatives 5-9 with 2'-deoxy-5-iodouridine 10 (Scheme 2). Tritylation at the primary hydroxyl group of 11-15 with DMTrCl and phosphitylation at the secondary hydroxyl group yielded phosphoramidites 21-25. The amidites 21-25 were incorporated into ONs using conventional solid-phase phosphoramidite synthesis and purified by reverse-phase HPLC. The ON sequences used in this study are shown in Table 2.

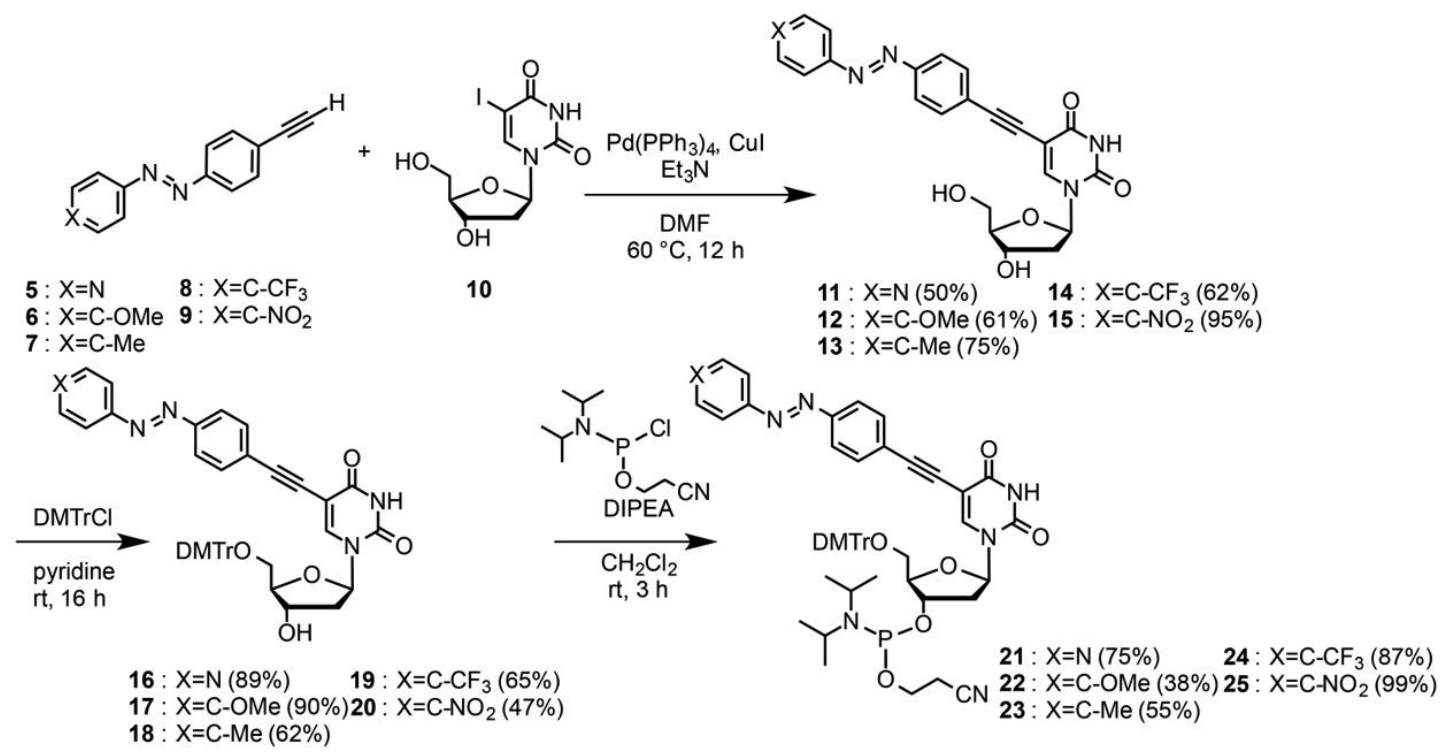

Scheme 2. Route for the synthesis of para-substituted $\mathbf{d} \mathbf{U}^{\mathbf{A z}}$ phosphoramidites. 
Table 2. The oligonucleotides used in this study.

\begin{tabular}{|c|c|c|}
\hline ON & Sequence & $\mathbf{X}$ \\
\hline 26 & 5'-d(GCGTTTTTTGCT)-3' & - \\
\hline 27 & 5'-d(GCGTTXTTTGCT)-3' & $\mathbf{d} \mathbf{U}^{\mathrm{Az}}$ \\
\hline 28 & 5'-d(GCGTTXTTTGCT)-3' & $\mathrm{dU}^{\mathrm{Az}}-\mathrm{OMe}$ \\
\hline 29 & 5'-d(GCGTTXTTTGCT)-3' & $\mathbf{d U}^{\mathrm{Az}}-\mathbf{M e}$ \\
\hline 30 & 5'-d(GCGTTXTTTGCT)-3' & $\mathbf{d U}^{\mathrm{Az}}-\mathbf{C F}_{\mathbf{3}}$ \\
\hline 31 & 5'-d(GCGTTXTTTGCT)-3' & $\mathrm{dU}^{\mathrm{Az}}-\mathrm{NO}_{2}$ \\
\hline 32 & 5'-d(GCGTTXTTTGCT)-3' & dU ${ }^{A z}$-pyridyl \\
\hline 33 & 5'-d(AGCAAAAAACGC)-3' & - \\
\hline 34 & 5'-r(AGCAAAAAACGC)-3' & - \\
\hline
\end{tabular}

\subsection{Isomerization Properties of Para-Substituted $\boldsymbol{d} \boldsymbol{U}^{A z}$ Analogues}

The influence of para-substitution on the efficiency of the $\mathbf{d} \mathbf{U}^{\mathbf{A z}}$ cis-trans photo-isomerization in ONs was investigated by UV spectroscopy and HPLC analysis. The photo-isomer ratio was measured at $260 \mathrm{~nm}$ because ONs $\mathbf{2 7 - 3 2}$ have the same extinction coefficient before and after irradiation at this wavelength (Figure S1). The wavelengths of light used for photo-isomerization and their efficiencies are shown in Table 3. Ten seconds of irradiation was confirmed to be enough for reaching photostationary state (PSS); the cis/trans ratios of ONs 27-32 after longer irradiation times (30 and $120 \mathrm{~min}$ ) were the same as that after $10 \mathrm{~s}$ of irradiation. Compared with ON 27 containing $\mathbf{d U}^{\mathbf{A z}}$, ONs 28 and 29 containing electron-donating substituted $\mathbf{d} \mathbf{U}^{\mathbf{A z}}$ were photo-isomerized from trans to cis more effectively. Irradiation of ON 28 (X $=\mathbf{d U}^{\mathbf{A z}}-\mathbf{O M e}$ ) using $365 \mathrm{~nm}$ afforded a mixture with $79 \%$ of the cis-form. In contrast, $\mathrm{ON} 30$ bearing the electron-withdrawing $\mathrm{CF}_{3}$ group showed a lower trans to cis isomerization efficiency. However, the cis to trans isomerization efficiency was higher than that of ON 27 containing $\mathbf{d} \mathbf{U}^{\mathbf{A z}}$. ONs $\mathbf{3 1}$ and 32 containing $\mathbf{d U}^{\mathbf{A z}}-\mathbf{N O}_{2}$ and $\mathbf{d U}^{\mathrm{Az}}$-pyridyl were barely photo-isomerized. The low efficiency of photo-isomerization was due to the low electron density at the azo-structure [23]. In case of $\mathbf{d U}^{\mathbf{A z}}$-pyridyl, electrons tend to be delocalized at the nitrogen of the pyridine ring [24]. ONs 28-31 were photo-isomerized trans to cis and vice versa for at least three cycles without any attenuation of efficiency.

Table 3. Photo-isomerization properties of para-substituted $\mathbf{d} \mathbf{U}^{\mathrm{Az} a}$.

\begin{tabular}{|c|c|c|c|c|c|c|}
\hline \multirow{2}{*}{$\mathrm{ON}^{b}$} & \multirow[t]{2}{*}{$\mathbf{X}$} & \multirow{2}{*}{$\begin{array}{c}\text { Before Photo- } \\
\text { Irradiation } \\
\text { Trans-Isomer/\% }^{b}\end{array}$} & \multicolumn{2}{|c|}{ Trans to Cis } & \multicolumn{2}{|c|}{ Cis to Trans } \\
\hline & & & Wavelength $c / \mathbf{n m}^{a}$ & cis-isomer/\% ${ }^{d}$ & Wavelength $^{c} / \mathbf{n m}^{a}$ & Trans-Isomer/\% ${ }^{d}$ \\
\hline 27 & $\mathbf{d} \mathbf{U}^{\mathrm{Az}}$ & 82 & 365 & 58 & 450 & 82 \\
\hline 28 & $\mathrm{dU}^{\mathrm{Az}}-\mathrm{OMe}$ & 59 & 365 & 79 & 450 & 59 \\
\hline 29 & $\mathrm{dU}^{\mathrm{Az}}-\mathrm{Me}$ & 77 & 365 & 61 & 450 & 77 \\
\hline 30 & $\mathrm{dU}^{\mathrm{Az}}-\mathrm{CF}_{\mathbf{3}}$ & 91 & 365 & 28 & 450 & 91 \\
\hline 31 & $\mathrm{dU}^{\mathrm{Az}}-\mathrm{NO}_{2}$ & 96 & 400 & 14 & 450 & 96 \\
\hline 32 & dU $U^{A z}$-pyridyl & 100 & - & 0 & - & - \\
\hline
\end{tabular}


Next, the thermo-stability of ONs with various para-substituted $\mathbf{d} \mathbf{U}^{\mathrm{Az}}$ in the cis-form was investigated [25]. The ONs modified with $\mathbf{d} \mathbf{U}^{\mathbf{A z}}$ analogues were cis-isomerized by the appropriate wavelength of light and subsequently heated to $60{ }^{\circ} \mathrm{C}$. The change in absorbance at $365 \mathrm{~nm}$ was monitored by a UV-Vis spectrophotometer and plotted to calculate the half-life of the cis-isomers (Table 4). With regard to ONs 28 and 29 containing electron-donating substituted $\mathbf{d} \mathbf{U}^{\mathrm{Az}}$, thermo-stabilities of the cis-isomer were significantly decreased. This phenomenon could be attributed to the para-electron-donating substituent and ethynyl linker creating a push-pull configuration of the azobenzene moiety, which is well known in easily thermo-isomerized azobenzene derivatives [18]. On the other hand, ONs 30 and 31 containing electron-withdrawing substituted $\mathbf{d U}^{\mathrm{Az}}$ showed long half-life times. The cis-isomer of ON $31\left(\mathbf{X}=\mathbf{d} \mathbf{U}^{\mathbf{A z}}-\mathbf{N O}_{2}\right)$ scarcely isomerized from cis to trans even when heated to $60{ }^{\circ} \mathrm{C}$ for more than $10 \mathrm{~h}$. In the case of ONs $\mathbf{3 0}$ and 31, both the ethynyl linker and para-substitution work as 4,4'-di-electron-withdrawing moieties. The 4,4'-di-electron-withdrawing substitution of azobenzene strengthens the thermal stability of the cis-form [26].

Table 4. Half-life time of the cis-form of para-substituted-dU $\mathbf{U}^{\mathbf{A z}}$ at $60{ }^{\circ} \mathrm{C}^{a}$.

\begin{tabular}{ccc}
\hline $\mathrm{ON}^{b}$ & $\mathbf{X}$ & $\mathrm{t}_{1 / 2}$ of cis-isomer/min. ${ }^{\mathrm{c}, \mathrm{d}}$ \\
\hline $\mathbf{2 7}$ & $\mathbf{d U ^ { \mathrm { Az } }}$ & 44 \\
$\mathbf{2 8}$ & $\mathbf{d U}^{\mathbf{A z}}-\mathbf{O M e}$ & 9 \\
$\mathbf{2 9}$ & $\mathbf{d U}^{\mathbf{A z}}-\mathbf{M e}$ & 24 \\
$\mathbf{3 0}$ & $\mathbf{d U}^{\mathrm{Az}}-\mathbf{C F}_{\mathbf{3}}$ & 65 \\
$\mathbf{3 1}$ & $\mathbf{d U}^{\mathrm{Az}}-\mathbf{N O} \mathbf{O}_{\mathbf{2}}$ & $>300$ \\
$\mathbf{3 2}$ & $\mathbf{d U}^{\mathbf{A z}}$-pyridyl & $-e$ \\
\hline
\end{tabular}

${ }^{a}$ Conditions: $10 \mathrm{mM} \mathrm{Na} 2 \mathrm{HPO}_{4}$ (pH 7.0), $100 \mathrm{mM} \mathrm{NaCl}, 4 \mu \mathrm{M} \mathrm{ON} ;{ }^{b} \mathrm{ON}$ sequence is 5'-d(GCGTTXTTTGCT)-3'; ${ }^{\mathrm{c}}$ trans- ONs were photo-isomerized to the cis-form by a 10 second irradiation of $365 \mathrm{~nm}$ (ONs 27-30) or $400 \mathrm{~nm}$ (ON 31) monochromic light; ${ }^{d}$ Half-life times of cis-isomers were measured at $60{ }^{\circ} \mathrm{C} ;{ }^{e} \mathrm{t}_{1 / 2}$ could not be determined because $\mathbf{d U ^ { A z }}$-pyridyl did not isomerize to the $c i s$-form.

The para-substitution would sterically and electronically affect the stability of the duplexes formed by $\mathbf{d U}^{\mathrm{Az}}$ analogue-modified ONs with complementary strands. Therefore, we investigated the $T_{\mathrm{m}}$ values of the duplexes formed between ON 28-32 and full match DNA or RNA (Tables 5 and 6). It was found that para-substitution of $\mathbf{d} \mathbf{U}^{\mathbf{A z}}$ slightly destabilized the DNA/DNA duplexes but had little influence on the DNA/RNA duplexes.

Table 5. $T_{\mathrm{m}}$ values of duplexes formed by $\mathbf{d \mathbf { U } ^ { \mathrm { Az } }}$ analogue-modified ONs with complementary DNA ${ }^{a}$.

\begin{tabular}{cccc}
\hline Duplex & $\mathbf{X}$ & $\boldsymbol{T}_{\mathrm{m}}\left[{ }^{\circ} \mathbf{C}\right]$ & $\Delta \boldsymbol{T}_{\mathrm{m}}\left[{ }^{\circ} \mathbf{C}\right]^{\boldsymbol{b}}$ \\
\hline $\mathbf{2 7 / 3 3}$ & $\mathbf{d U}^{\mathrm{Az}}$ & 47 & - \\
$\mathbf{2 8} / \mathbf{3 3}$ & $\mathbf{d U}^{\mathrm{Az}}-\mathbf{O M e}$ & 44 & -3 \\
$\mathbf{2 9 / 3 3}$ & $\mathbf{d U}^{\mathrm{Az}}-\mathbf{M e}$ & 45 & -2 \\
$\mathbf{3 0 / 3 3}$ & dU $^{\mathrm{Az}}-\mathbf{C F}_{3}$ & 45 & -2 \\
$\mathbf{3 1 / 3 3}$ & dU $^{\mathrm{Az}}-\mathbf{N O}_{2}$ & 45 & -2 \\
$\mathbf{3 2 / 3 3}$ & dU $^{\mathrm{Az}}$-pyridyl & 44 & -3 \\
\hline
\end{tabular}

${ }^{a}$ Conditions: $10 \mathrm{mM} \mathrm{Na}_{2} \mathrm{HPO}_{4}(\mathrm{pH} 7.0), 100 \mathrm{mM} \mathrm{NaCl}, 4 \mu \mathrm{M}$ ON. The $T_{\mathrm{m}}$ values given are the average of at least three data points. The $T_{\mathrm{m}}$ value of natural DNA 26/DNA 33 duplex is $52{ }^{\circ} \mathrm{C}$; ${ }^{b}$ The $\Delta T_{\mathrm{m}}$ indicates the difference from ON 27/DNA 33 duplex. 
Table 6. $T_{\mathrm{m}}$ values of duplexes formed by $\mathbf{d \mathbf { U } ^ { \mathrm { Az } }}$ analogue-modified ONs with complementary RNA ${ }^{a}$.

\begin{tabular}{cccc}
\hline Duplex & $\mathbf{X}$ & $\boldsymbol{T}_{\mathbf{m}}\left[{ }^{\circ} \mathbf{C}\right]$ & $\Delta \boldsymbol{T}_{\mathbf{m}}\left[{ }^{\circ} \mathbf{C}\right]^{\boldsymbol{c}}$ \\
\hline $\mathbf{2 7 / 3 4}$ & $\mathbf{d U}^{\mathrm{Az}}$ & 42 & - \\
$\mathbf{2 8 / 3 4}$ & dU $^{\mathrm{Az}}-\mathbf{O M e}$ & 41 & -1 \\
$\mathbf{2 9 / 3 4}$ & $\mathbf{d U}^{\mathrm{Az}}-\mathbf{M e}$ & 43 & +1 \\
$\mathbf{3 0 / 3 4}$ & $\mathbf{d U}^{\mathrm{Az}}-\mathbf{C F}_{\mathbf{3}}$ & 41 & -1 \\
$\mathbf{3 1 / 3 4}$ & $\mathbf{d U}^{\mathrm{Az}}-\mathbf{N O}_{2}$ & 41 & -1 \\
$\mathbf{3 2 / 3 4}$ & dU $^{\mathrm{Az}}$-pyridyl & 42 & 0 \\
\hline
\end{tabular}

${ }^{a}$ Conditions: $10 \mathrm{mM} \mathrm{Na}_{2} \mathrm{HPO}_{4}(\mathrm{pH} 7.0), 100 \mathrm{mM} \mathrm{NaCl}, 4 \mu \mathrm{M}$ ON. The $T_{\mathrm{m}}$ values given are the average of at least three data points. The $T_{\mathrm{m}}$ value of natural DNA 26/RNA 34 duplex is $47{ }^{\circ} \mathrm{C} ;{ }^{b}$ The $\Delta T_{\mathrm{m}}$ indicates the difference from ON 27/RNA 34 duplex.

The changes in $T_{\mathrm{m}}$ values of $\mathbf{d U}^{\mathbf{A z}}$-modified duplexes upon photo-irradiation could not be determined due to the low thermal stability of the cis-form itself (ONs $\mathbf{2 8}$ and 29, Table 4) or low trans to cis photo-isomerization efficiency (ONs 30-32, Table 3). Therefore, we investigated the changes in the thermodynamic stabilities of 12-bp DNA/RNA duplexes containing $\mathbf{d U}^{\mathbf{A z}} \mathbf{- O M e}$ and $\mathbf{d} \mathbf{U}^{\mathbf{A z}} \mathbf{-} \mathbf{M e}$ upon photo-irradiation by isothermal titration calorimetry (ITC) at $25^{\circ} \mathrm{C}$ (Table 7). $1 \mu \mathrm{M}$ of complementary RNA strand in the syringe was titrated to $0.1 \mu \mathrm{M} \mathbf{d U}^{\mathrm{Az}}$ analogue-modified $\mathrm{ON}$ in the cell and the heat transfer during binding was measured to determine the thermodynamic parameters of DNA/RNA duplex formation. The experiments were conducted for $\mathbf{d} \mathbf{U}^{\mathbf{A z}}$ analogue-modified ONs both before and after irradiation. Duplex 28/34 showed a lower Gibbs free energy change $(\Delta G)$ after photo-irradiation than that before photo-irradiation. This trend was also observed in duplex 29/34. These results indicate that the hybridization abilities of ONs modified with $\mathbf{d} \mathbf{U}^{\mathbf{A z}}-\mathbf{O M e}$ and $\mathbf{d} \mathbf{U}^{\mathbf{A z}}-\mathbf{M e}$ can be regulated by the appropriate wavelength of light, as with the case of $\mathbf{d} \mathbf{U}^{\mathbf{A z}}$.

Table 7. Thermodynamic parameters of duplexes formed by $\mathbf{d} \mathbf{U}^{\mathbf{A z}}$ analogue-modified ONs with complementary RNA ${ }^{a}$.

\begin{tabular}{cccccc}
\hline Duplex & $\mathbf{X}$ & $\boldsymbol{K}_{\mathrm{a}} \times \mathbf{1 0}^{\mathbf{7}}[\mathbf{M}]$ & $\Delta \boldsymbol{H}[\mathrm{kcal} / \mathbf{m o l}]$ & $\Delta \boldsymbol{S}[\mathrm{kcal} / \mathbf{m o l} / \mathbf{d e g}]$ & $\Delta \boldsymbol{G}[\mathrm{kcal} / \mathbf{m o l}]$ \\
\hline $\mathbf{2 8 / 3 4}$ & $\mathbf{d U}^{\mathrm{Az}}-\mathbf{O M e}$ & $2.65 \pm 0.317$ & $-54.1 \pm 0.839$ & -0.148 & -9.97 \\
& $\mathbf{d U}^{\mathrm{Az}}-\mathbf{O M e}{ }^{b}$ & $3.03 \pm 0.600$ & $-54.8 \pm 1.50$ & -0.150 & -10.1 \\
$\mathbf{2} 2 / 34$ & $\mathbf{d U}^{\mathrm{Az}}-\mathbf{M e}$ & $2.17 \pm 0.414$ & $-55.3 \pm 1.60$ & -0.152 & -9.98 \\
& $\mathbf{d U}^{\mathrm{Az}}-\mathbf{M e}^{b}$ & $4.15 \pm 0.798$ & $-52.1 \pm 1.20$ & -0.140 & -10.4 \\
\hline
\end{tabular}

${ }^{a}$ Conditions: $5 \mathrm{mM} \mathrm{Na}_{2} \mathrm{HPO}_{4}\left(\mathrm{pH} 7.0\right.$ ), $50 \mathrm{mM} \mathrm{NaCl}, 0.1 \mu \mathrm{M} \mathrm{dU}{ }^{\mathrm{Az}}$ modified ON (titrand); $5 \mathrm{mM} \mathrm{Na}_{2} \mathrm{HPO}_{4}$ (pH 7.0), $50 \mathrm{mM} \mathrm{NaCl}, 1 \mu \mathrm{M}$ complementary RNA strand (titrant). ${ }^{b}$ After photo-irradiation at $365 \mathrm{~nm}$ for $10 \mathrm{~s}$.

\section{Discussion}

As shown above, para-substitution strongly affected the photo-isomerization efficiency of $\mathbf{d} \mathbf{U}^{\mathbf{A z}}$. It is important to modulate the electron nature of the azo structure for the optimization of $\mathbf{d U}^{\mathbf{A z}}$ photo-isomerization properties. Notably, the electron-donating OMe group could strongly bias the equilibrium to the cis-isomer after irradiation at $365 \mathrm{~nm}$. This would contribute to the enhancement of the properties of $\mathbf{d} \mathbf{U}^{\mathbf{A z}}$ in the "on" state. On the other hand, electron-withdrawing $\mathrm{CF}_{3}$ and $\mathrm{NO}_{2}$ groups strongly biased the equilibrium to the trans form before irradiation. This could suppress the undesired expression of $\mathbf{d} \mathbf{U}^{\mathbf{A z}}$ properties such as the hybridization ability before irradiation. 
Modulating the rate of the thermal relaxation of the switched state is also very important because it realizes the spatiotemporal control of nucleic acid properties [27]. The thermal stability of the cis-isomer influences the method of utilization of photo-switches. cis-ON $28\left(\mathbf{X}=\mathbf{d} \mathbf{U}^{\mathbf{A z}} \mathbf{- O M e}\right)$ showed the shortest thermal half-life among the $\mathbf{d U ^ { \mathbf { A z } }}$ analogue-modified ONs that we evaluated. This property is crucial for a photo-switch that thermally relaxes the hybridization ability. This would enable repeated activation with spatiotemporal resolution. On the other hand, ONs 30 and $\mathbf{3 1}\left(\mathbf{X}=\mathbf{d U}^{\mathbf{A z}}-\mathbf{C F}_{\mathbf{3}}\right.$ and $\mathbf{d U}^{\mathbf{A z}}-\mathbf{N O}_{2}$ ) have a long half-life of the cis-form. In this case, it is possible to turn the hybridization property of $\mathbf{d} \mathbf{U}^{\mathbf{A z}}$ on and off using the appropriate wavelength of light.

The para substitutions decreased the affinity of ONs modified with $\mathbf{d} \mathbf{U}^{\mathbf{A z}}$ analogues against DNA but had little influence on that against RNA. These results suggest that para substitutions influence the duplex stability not electronically but sterically. The difference in the stability between DNA/DNA duplexes and DNA/RNA duplexes is attributed to the difference in the duplex structures. DNA/DNA duplexes tend to have B-form structures whereas DNA/RNA duplexes tend to have more A-form structures. Thus, the DNA/DNA duplex has a comparatively shallow major groove and para-substitution of the azobenzene moiety may sterically destabilize the duplex. The destabilization of duplexes in the trans-form may lead to an increase in the difference of hybridization ability between trans- and cis-d $\mathbf{U}^{\mathbf{A z}}$ and improve the property of $\mathbf{d} \mathbf{U}^{\mathbf{A z}}$ for photo-switching hybridization.

We introduced various para substitutions into $\mathbf{d} \mathbf{U}^{\mathbf{A z}}$ and modulated the photo- and thermo-sensitivities for trans-cis isomerization. Our results represent an important strategy for optimization of the properties of photo-switches. For example, $\mathbf{d U}^{\mathbf{A z}} \mathbf{- O M e}$ showed better trans to cis isomerization efficiency and lower thermal stability of the cis-isomer than $\mathbf{d U}^{\mathbf{A z}}$. This analogue could be utilized as a useful photo-switch for situations in which a fast drop in activity is desired. $\mathbf{d} \mathbf{U}^{\mathbf{A z}}$-modified $\mathrm{ON}$ shows an interesting hybridization property, namely the affinity of the cis-form against complementary strands is higher than that of the trans-form, different from most other photo-switches [16]. Para-substituted $\mathbf{d U}^{\mathbf{A z}}$ analogues have the potential for unique nucleic acid probes and drugs that reversibly capture the target DNA and RNA with spatiotemporal control.

\section{Conclusions}

We synthesized photo-isomeric $\mathbf{d} \mathbf{U}^{\mathbf{A z}}$ analogues bearing various para-substituted azobenzene derivatives and investigated the influence of the para substitution on the photo-isomerization properties, thermal stabilities of the cis-isomer, and hybridization abilities. Electron-withdrawing substituents on $\mathbf{d U}^{\mathbf{A z}}$ lowered the efficiency of photo-isomerization while improving the thermal stability of the cis-isomer. On the other hand, electron-donating substituents improved the efficiency of photo-isomerization while decreasing the thermal stability of the cis-isomer. According to UV-melting experiments, para-substitution of $\mathbf{d} \mathbf{U}^{\mathbf{A z}}$ tended to destabilize DNA/DNA duplexes but had little effect on the stabilities of the DNA/RNA duplexes regardless of the nature of the substituents. ITC experiments revealed that the duplex formed between $\mathbf{d U}^{\mathbf{A z}}$-OMe-modified ON and complementary RNA are more stable after photo-irradiation than that before photo-irradiation. This trend was observed in the duplex formed between $\mathbf{d U}^{\mathrm{Az}}$-Me-modified $\mathrm{ON}$ and complementary RNA. These results indicated that $\mathbf{d U}^{\mathbf{A z}} \mathbf{- O M}_{\mathbf{O}} \mathbf{O}$ and $\mathbf{d} \mathbf{U}^{\mathbf{A z}}$-Me could regulate the stability of the DNA/RNA duplex by photo-irradiation similar to $\mathbf{d} \mathbf{U}^{\mathbf{A z}}$ and appropriate substitution could optimize the properties of $\mathbf{d} \mathbf{U}^{\mathbf{A z}}$ as light-responsive nucleic acid probes. 


\section{Acknowledgments}

A part of this work was supported by KAKENHI from the Japan Society for the Promotion of Science (JSPS) and the Basic Science and Platform Technology Program for Innovative Biological Medicine from the Ministry of Education, Culture, Sports, Science and Technology (MEXT).

\section{Author Contributions}

K.M. and S.O. designed the research. S.M., K.M. and Y.K. performed the experiments and analyzed the data. S.M. was mainly responsible for writing the manuscript, with contributions from K.M., S.T. and S.O.

\section{Conflicts of Interest}

The authors declare no conflict of interest.

\section{References}

1. Tashiro, R.; Sugiyama, H. Biomolecule-based switching devices that respond inversely to thermal stimuli. J. Am. Chem. Soc. 2005, 127, 2094-2097.

2. Hatano, A.; Makita, S.; Kirihara, M. Synthesis and redox-active base-pairing properties of DNA incorporating mercapto C-nucleosides. Tetrahedron 2005, 61, 1723-1730.

3. Wada, T.; Minamimoto, N.; Inaki, Y.; Inoue, Y. Peptide ribonucleic acid (PRNA). 2. A novel strategy for active control of DNA recognition though borate ester formation. J. Am. Chem. Soc. 2000, 122, 6900-6910.

4. Monroe, W.T.; McQuain, M.M.; Chang, M.S.; Alexander, J.S.; Haselton, F.R. Targeting expression with light using caged DNA. J. Biol. Chem. 1999, 274, 20895-20900.

5. Asanuma, H.; Ito, T.; Yoshida, T.; Liang, X.; Komiyama, M. Photoregulation of the formation and dissociation of a DNA duplex by using the cis-trans isomerization of azobenzene. Angew. Chem. Int. Ed. Engl. 1999, 38, 2393-2395.

6. Szymanski, W.; Beierie, J.M.; Kistemaker, H.A.V.; Velema, W.A.; Feringa, B.L. Reversible photocontrol of biological systems by the incorporation of molecular photoswitches. Chem. Rev. 2013, 113, 6114-6178.

7. Cahova, H.; Jaschke, A. Nucleoside-based diarylethene photoswitches and their facile incorporation into photoswitchable DNA. Angew. Chem. Int. Ed. 2013, 52, 3186-3190.

8. Barrois, S.; Wagenknecht, H.A. Diarylethene-modified nucleotides for switching optical properties in DNA. Beilstein J. Org. Chem. 2012, 8, 905-914.

9. Ogasawara, S.; Maeda, M. Straightforward and reversible photoregulation of hybridization by using a photochromic nucleoside. Angew. Chem. Int. Ed. 2008, 47, 8839-8842.

10. Ogasawara, S.; Maeda, M. Photoresponsive 5'-cap for the reversible photoregulation of gene expression. Bioorg. Med. Chem. Lett. 2011, 21, 5457-5459.

11. Ogasawara, S. Control of cellular function by reversible photoregulation of translation. Chem. Bio. Chem. 2014, 15, 2652-2655. 
12. Goodsell, D.S. The molecular perspective: Ultraviolet light and pyrimidine dimers. Oncologist 2001, 6, 298-299.

13. Asanuma, H.; Matsunaga, D.; Komiyama, M. Clear-cut photo-regulation of the formation and dissociation of the DNA duplex by modified oligonucleotide involving multiple azobenzenes. Nucleic Acids Symp. Ser. 2005, 49, 35-36.

14. Nishioka, H.; Liang, X.; Kashida, H.; Asanuma, H. 2',6'-Dimethylazobenzene as an efficient and thermo-stable photoregulator for the photoregulation of DNA hybridization. Chem. Commun. 2007, doi:10.1039/b708952j.

15. Kamiya, Y.; Asanuma, H. Light-driven DNA nanomachine with a photoresponsive molecular engine. Acc. Chem. Res. 2014, 47, 1663-1672.

16. Mori, S.; Morihiro, K.; Obika, S. C5-azobenzene-substituted 2'-deoxyuridine-containing-oligodeoxynucleotides for photo-switching hybridization ability. Molecules 2014, 19, 5109-5118.

17. Beharry, A.A.; Woolley, G.A. Azobenzene photoswitches for biomolecules. Chem. Soc. Rev. 2011, 40, 4422-4437.

18. Zenkina, O.; Altman, M.; Leitus, G.; Shimon, L.J.W.; Cohen, R.; van Der Boom, M.E. From azobenzene coordination to aryl-halide bond activation by platinum. Organometallics 2007, 26, 4528-4534.

19. Kubischke, J.; Nather, C.; Herges, R. Synthesis of functionalized triazatriangulenes for application in photo-switchable self-assembled monolayers. Eur. J. Org. Chem. 2010, 26, 5041-5055.

20. Miao, Z.; Zhang, Y.; Zhao, Y.; Wang, Z.; Wang, D. Asymmetrical azobenzene liquid crystals with high birefringence prepared via click chemistry. Mol. Cryst. Liq. Cryst. 2014, 591, 10-18.

21. McDonagh, A.M.; Cifuentes, M.P.; Lucas, N.T.; Humphrey, M.G.; Houbrechts, S.; Persoons, A. Organometallic complexes for nonlinear optics Part 20. Syntheses and molecular quadratic hyperpolarizabilities of alkynyl complexes derived from (E)-4,4-HCCC6H4N=NC6H4NO2. J. Organomet. Chem. 2000, 605, 193-201.

22. Sonogashira, K.; Tohda, Y.; Hagihara, N. A convenient synthesis of acetylenes: Catalytic substitutions of acetylenic hydrogen with bromoalkenes, iodoarenes and bromopyridines. Tetrahedron Lett. 1975, 16, 4467-4470.

23. Dhammika, H.M.; Burdette, S.C. Photoisomerization in different classes of azobenzene. Chem. Soc. Rev. 2012, 41, 1809-1825.

24. Nakagawa, M.; Rikukawa, M.; Watanabe, M.; Sanui, K.; Ogata, N. Electrochemical and photochromic properties of azopyridinium methylsulfates. Chem. Lett. 1994, 23, 1785-1788.

25. Takaishi, K.; Kawamoto, M. Synthesis and conformation of substituted chiral binaphthyl-azobenzene cyclic dyads with chiroptical switching capabilities. Molecules 2011, 16, 1603-1624.

26. Dokic, J.; Gothe, M.; Wirth, J.; Peters, M.V.; Schwarz, J.; Hecht, S.; Saalfrank, P. Quantum chemical investigation of thermal cis-to-trans isomerization of azobenzene derivatives: Substituent effects, solvent effects and comparison to experimental data. J. Phys. Chem. A 2009, 113, 6763-6773.

27. Velema, W.A.; Szymanski, W.; Feringa, B.L. Photopharmacology: Beyond proof of principle. J. Am. Chem. Soc. 2014, 136, 2178-2191.

(C) 2015 by the authors; licensee MDPI, Basel, Switzerland. This article is an open access article distributed under the terms and conditions of the Creative Commons Attribution license (http://creativecommons.org/licenses/by/4.0/). 